\title{
Review Article \\ Histopathological Evaluation of Contrast-Induced Acute Kidney Injury Rodent Models
}

\author{
Norbert Kiss and Péter Hamar \\ Institute of Pathophysiology, Semmelweis University, Budapest, Hungary \\ Correspondence should be addressed to Péter Hamar; hampet@net.sote.hu
}

Received 13 July 2016; Revised 6 October 2016; Accepted 19 October 2016

Academic Editor: Jiang Du

Copyright ( 2016 N. Kiss and P. Hamar. This is an open access article distributed under the Creative Commons Attribution License, which permits unrestricted use, distribution, and reproduction in any medium, provided the original work is properly cited.

\begin{abstract}
Contrast-induced acute kidney injury (CI-AKI) can occur in 3-25\% of patients receiving radiocontrast material (RCM) despite appropriate preventive measures. Often patients with an atherosclerotic vasculature have to receive large doses of RCM. Thus, animal studies to uncover the exact pathomechanism of CI-AKI are needed. Sensitive and specific histologic end-points are lacking; thus in the present review we summarize the histologic appearance of different rodent models of CI-AKI. Single injection of RCM causes overt renal damage only in rabbits. Rats and mice need an additional insult to the kidney to establish a clinically manifest CI-AKI. In this review we demonstrate that the concentrating ability of the kidney may be responsible for species differences in sensitivity to CI-AKI. The most commonly held theory about the pathomechanism of CI-AKI is tubular cell injury due to medullary hypoxia. Thus, the most common additional insult in rats and mice is some kind of ischemia. The histologic appearance is tubular epithelial cell (TEC) damage; however severe TEC damage is only seen if RCM is combined by additional ischemia. TEC vacuolization is the first sign of CI-AKI, as it is a consequence of RCM pinocytosis and lysosomal fusion; however it is not sensitive as it does not correlate with renal function and is not specific as other forms of TEC damage also cause vacuolization. In conclusion, histopathology alone is insufficient and functional parameters and molecular biomarkers are needed to closely monitor CI-AKI in rodent experiments.
\end{abstract}

\section{Introduction}

Contrast-induced acute kidney injury (CI-AKI) is defined as an increase of $>25 \%$ or $>0.5 \mathrm{mg} / \mathrm{dL}(44 \mu \mathrm{mol} / \mathrm{L})$ serum creatinine $\left(S_{\mathrm{Cr}}\right)$ from baseline within $48-72$ hours following intravenous injection of iodine-based radiocontrast material (RCM) if other causes of renal impairment can be excluded [1-3]. CI-AKI is the third most common cause of hospital acquired acute renal failure $[2,4,5]$ and is responsible for about $10-12 \%$ of the cases [2, 6-8]. Renal function may deteriorate after RCM use even in the absence of overt CIAKI $[9,10]$. CI-AKI was first reported in 1942 [11]. The rise in the use of intravenous RCM for computer tomography (CT) and magnetic resonance imaging (MRI) and angiography [5] (Figure 1) led to the recognition of CI-AKI as the most important complication of iodinated RCM administration. Although contrast enhanced X-ray is the most common indication of RCM use (Figure 1), percutaneous coronary angiography (in the USA: 1.4-1.3 million/year between 1997 and 2010 [12]) is the primary cause of CI-AKI [4, 5]. Although hydration is considered to be the most effective preventive measure [13, 14], CI-AKI may develop in 3-25\% of patients despite appropriate hydration [15] and further preventive measures such as antioxidants $[2,16]$ or statins $[4,17]$. However, the affected patient population is much larger considering subclinical cases [9]. Furthermore, RCM administration in patients with high risk of CI-AKI such as preexisting renal problems [18] or the use of large RCM doses [19] is often unavoidable, which underscores the need for effective prevention strategies.

Although hypoxia of the renal medulla [20-22] due to reduction of renal blood flow (RBF) especially in peritubular capillaries [23] and consequent oxidative stress are thought to be the major effectors of CI-AKI [13, 24-26], the exact pathomechanism is unknown $[15,20]$. Thus CI-AKI is a subject of intense research. In-depth analysis of molecular pathophysiology requires animal models. Therefore, different rodent models, such as mice, rats, and also rabbits, are commonly 


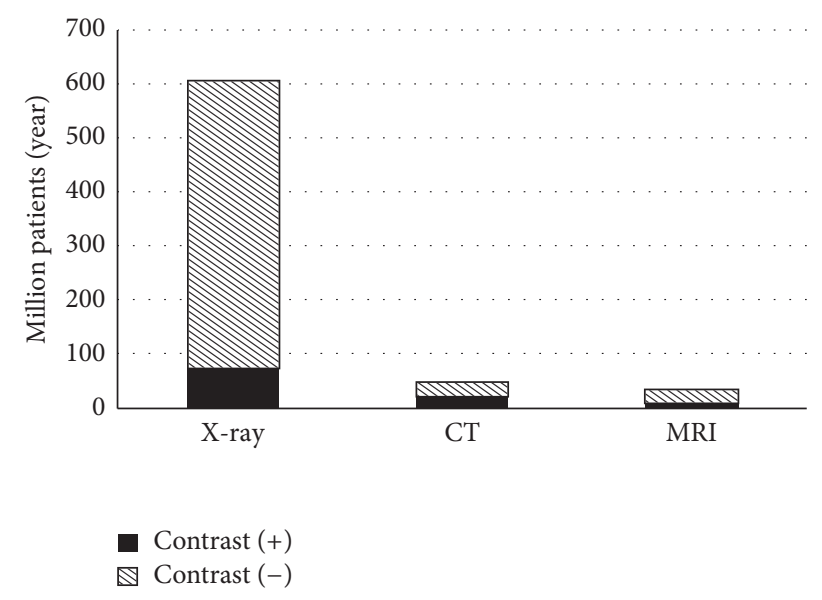

FIgURE 1: Use of contrast materials in the USA. The most common cause of intravenous iodinated contrast media [27] is X-ray (75 million/year) while about $50 \%$ of the CT and MRI studies are also contrast enhanced accounting for another 38 million patients/year. The degree of contrast utilization is expected to increase in the future [28]. The global market for radiopharmaceuticals is $\$ 4.5$ billion in 2015 and is projected to reach US\$ 6.63 billion by 2017 [29]. The iodinated, injectable contrast agents segment is expected to account for the largest share of the contrast agents market [30].

applied in CI-AKI research. Histopathological analysis of the kidney can provide a definitive end-point in various experimental settings. However, the pathological appearance can vary between experimental models and a detailed description of CI-AKI histopathology is not available. Many of the experimental models also involve additional insults beside RCM; hence it is relevant to differentiate between specific and nonspecific histopathological lesions. In the present review we summarize the histopathological findings in CI-AKI rodent models.

\section{RCM Classes and Their Osmolality and Viscosity}

The type $[5,7]$ of the contrast material has been suggested as a risk factor for CI-AKI. The first generation of RCM were cheaper, ionic, and hyperosmotic (HOCM > $1000 \mathrm{mOsm} / \mathrm{L})$ (Table 1). Second-generation RCM are more expensive [18, 38], nonionic, low-osmolality RCM (LOCM: 600$900 \mathrm{mOsm} / \mathrm{L}$ ) where iodine is covalently bound to an organic component (Table 1). The newest generation of RCM, introduced in the $80 \mathrm{~s}$, is isoosmotic (IOCM: $280-320 \mathrm{mOsm} / \mathrm{L}$ ) with a dimeric structure. Although the osmolality of the RCM was held responsible for CI-AKI previously, the withdrawal of HOCM did not reduce the incidence of CI-AKI [39]. Moreover, clinical studies including a recent meta-analysis [40] did not find differences in the incidence of CI-AKI or renal safety profile between LOCM and HOCM [41, 42]. The osmolality of tested RCM did not influence the extent of tubular cell vacuolization in rats [43]. Similarly, our mouse (NMRI) model did not confirm the hypothesis that higher osmolality is more deleterious. Functional (survival, plasma urea) and morphological (tubular damage index) end-points were similar after LOCM (iomeprol) and HOCM (diatrizoate) (unpublished). A recent study comparing HOCM and IOCM concluded that IOCM was retained longer in the kidneys. The explanation for longer renal handling was the higher viscosity of IOCM due to their dimer structure and the lack of osmotic diuresis [44]. Resistance to flow is linearly proportional with the viscosity of the fluid and the length of the vessel and inversely proportional to the fourth power of the vessel radius (Poiseuille's law). Thus, viscosity and not osmolality determines flow especially in narrow and long peritubular capillaries [45-47]. In order to reduce toxicity, high viscosity RCM is warmed up to $37^{\circ} \mathrm{C}$ before administration reducing viscosity with about $50 \%$ (Table 1). Despite warming, several studies suggested that dimer IOCM is more toxic than monomer LOCM (Table 1) [45-47]. Furthermore, viscosity increases exponentially in the tubules during the concentrating procedure leading to slower tubular flow [46]. Thus, hydration may be beneficial by reducing urine concentration and viscosity in tubules [44-46]. Interestingly, the comparison of the highest viscosity iohexol (Omnipaque) ${ }^{\circledR}$ and the lowest viscosity metrizoate (isopaque) did not support the role of high viscosity in CI-AKI, as metrizoate caused more renal damage compared to iohexol [48-50]. A recent metaanalysis concluded that there is no difference in nephrotoxicity among various RCM owing to differences in ionicity, osmolality, or viscosity [51]. High viscosity could be a risk factor in insufficiently hydrated patients as hydration may be especially effective in preventing CI-AKI caused by high viscosity IOCM [45].

\section{Differences between Human and Rodent Kidneys}

Anatomically, rodents generally have a one-papilla kidney compared to the multi-papilla (4-18) human kidneys. The anatomic zones are similar $[52,53]$. Mice have on average 14000 and rats 22 000-25 000 [54] nephrons whereas humans can vary from 200000 to 1.8 [55] or up to 2.7 [53] million nephrons. The mouse glomerulus is around $70 \mu \mathrm{m}$, whereas the human glomerulus is $200 \mu \mathrm{m}$ in diameter [52]. The distal tubule has a brush border in mice but not in humans [52]. The outer stripe of the outer medulla in rodents is much more developed than in the human kidney (Figure 2). The supporting connective tissue is more prominent in humans than in mice [52]. Importantly, cortical proximal tubular epithelial cells can be vacuolated in male mice [52]. Furthermore, nephrogenesis is complete in humans at term birth whereas, in rodents, the majority of nephrons are formed after birth [53].

Functionally, the renal concentrating ability is higher in rodents than in humans, especially in mice (4000 mOsm/kg) [56] but not in rabbits (Table 2). The higher concentrating ability in mice is due to the complex, large bundles of vasa recta, which envelop the thin loop of Henle in mice. In humans, loops of Henle and vasa recta are simple and separated. Furthermore, the higher ratio ( $3: 1$ versus $7: 1$ in human) of long-loop-of-Henle nephrons over short ones contributes 
TABLE 1: Viscosity and osmolality of the 3 generations of radiocontrast materials (RCM). The iodine/molecule ratio is $1.5: 1$ in high-osmolality contrast media (HOCM), $3: 1$ in LOCM (tri-iodinated molecules), and 6:1 in IOCM dimers [61].

\begin{tabular}{|c|c|c|c|c|c|c|c|}
\hline \multirow{2}{*}{$\begin{array}{l}\text { Osmol. group } \\
\text { (intro.) }\end{array}$} & \multicolumn{2}{|r|}{ Name } & \multirow{2}{*}{ Chem struct } & \multicolumn{2}{|c|}{ Viscosity (mPa) } & \multirow{2}{*}{$\begin{array}{l}\text { Osmolality (m) } \\
\mathrm{mOsm} / \mathrm{kg} \mathrm{H}_{2} \mathrm{O}\end{array}$} & \multirow{2}{*}{ Year intro. } \\
\hline & Chemical & Brand & & $\left(20^{\circ} \mathrm{C}\right)$ & $\left(37^{\circ} \mathrm{C}\right)$ & & \\
\hline \multirow{2}{*}{ Isoosmotic (IOCM) (1990s) } & Iodixanol & Visipaque & \multirow{2}{*}{ Nonionic dimer } & 26.6 & 11.1 & 290 & 1996 \\
\hline & Iotrolan & Iovist & & 6.8 & 9.5 & 320 & 1989 \\
\hline \multirow{8}{*}{ Low (LOCM) (1980s) } & Ioxaglate & Hexabrix & \multirow{8}{*}{ Nonionic monomer } & 15.7 & 7.5 & 600 & 1985 \\
\hline & Ioxilan & Oxilan & & 16.3 & 7.8 & 695 & 1995 \\
\hline & Iomeprol & Imeron & & 15.6 & 8.1 & 726 & 1994 \\
\hline & Iopromide & Ultravist & & 22 & 9.5 & 770 & 1995 \\
\hline & Iohexol & Omnipaque & & 20.4 & 11.2 & 780 & 1985 \\
\hline & Ioversol & Optiray & & 18 & 8.5 & 792 & 1988 \\
\hline & Iopamidol & Isovue & & 20.9 & 9.8 & 796 & 1997 \\
\hline & Iobitridol & Xenetix & & 21 & 10 & 915 & 1994 \\
\hline \multirow{3}{*}{ High (HOCM) (1950s) } & Diatrizoate & Crystographin Hypaque & \multirow{3}{*}{ Ionic monomer } & 18.5 & 8.4 & 2000,1550 & 1955 \\
\hline & Metrizoate & Isopaque & & NA & 3.4 & 2100 & 1959 \\
\hline & Iothalamate & Conray & & NA & 9 & 2400 & 1962 \\
\hline
\end{tabular}

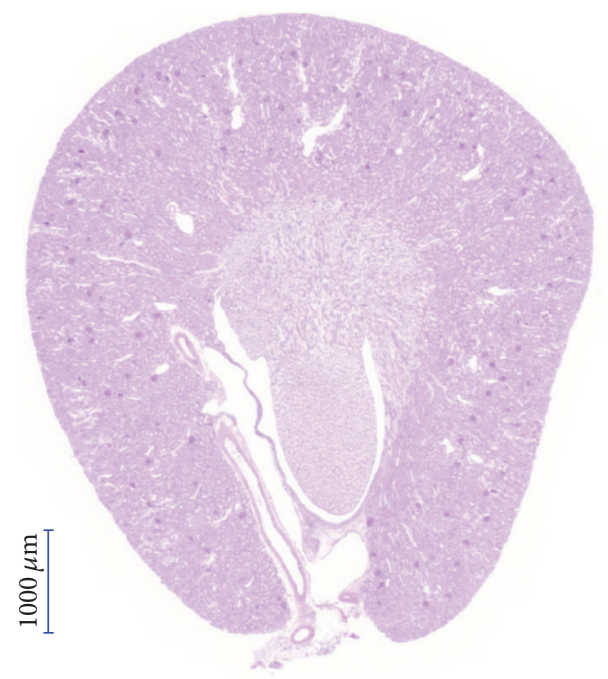

(a)

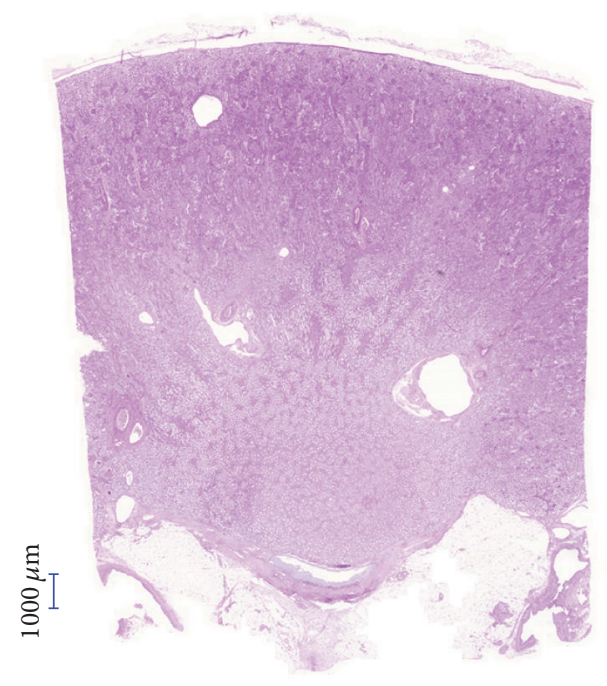

(b)

FIGURE 2: Comparison of mouse and human kidney. The one-papilla mouse kidney has a well developed outer stripe (a) (own picture), whereas this zone is much less prominent in the multipapilla human kidney (b) (courtesy of Attila Fintha, Semmelweis University, 2nd Department of Pathology) (magnification: 10x, PAS staining).

to the higher concentrating ability in mice [53]. Also, proteinuria is $<150 \mathrm{mg} /$ day and is mainly uromodulin (TammHorsfall protein) in healthy humans, whereas both mouse (0.6-3.1 mg/day) [57] and rat (2-15 mg/day) males (but not females) have considerable proteinuria [58] with an age dependent increase in glomerular filtration of large proteins, such as albumin, and decrease in sex dependent proteins [59]. Age dependent proteinuria is due to age related chronic progressive nephropathy $(\mathrm{CPN})$ in rats [60].

\section{Rodent Models of CI-AKI}

A single injection of iodine containing RCM ( $5 \mathrm{~g} / \mathrm{kg}$ ioxilan) induces CI-AKI only in rabbits $[87,88]$ but does not cause overt kidney damage in rats and mice [74, 89]. Therefore, rabbits offer more reliable model; however, rabbit facilities are not as common as mouse or rat facilities as rabbits are much more expensive to keep. Although tubular epithelial cell vacuolization was described in rats following a single injection of RCM without additional kidney pathology [72, 90, 91], vacuolization alone is not specific enough as a sole end-point to demonstrate CI-AKI. Although functional and histological damage was absent, molecular changes (increased adenosine receptor expressions) were induced by a single iodixanol injection even in mice [92]. To induce a clinically relevant and functionally obvious CI-AKI in rats and mice a combination of injuries is required (Table 3 ). 
TABLE 2: Differences between human and rodent kidney, summarized from [53] with additional data for human [52, 53, 62], mouse [42, 56, 63], and rabbit and rat $[53,64]$ species.

\begin{tabular}{lcccc}
\hline & Human & Rabbit & Rat & Mouse \\
\hline Number of papillas & $7-9$ & 1 & 1 & 1 \\
Number of nephrons & $0.2-2$ million & 30000 & $25-35000$ & 3000 \\
Concentrating ability $(\mathrm{mOsmol} / \mathrm{kg})$ & 1200 & 1400 & 140000 \\
Glomerular diameter $(\mu \mathrm{m})$ & 200 & 120 & 4000 \\
\hline
\end{tabular}

TABLE 3: Rat and mouse models of CI-AKI.

\begin{tabular}{|c|c|c|c|c|}
\hline Injury type (besides RCM injection) & Species & Advantage & Disadvantage & Ref. \\
\hline Inhibition of vasodilators & & $\begin{array}{c}\text { Pronounced medullary } \\
\text { hypoxia }\end{array}$ & Multiple insults & \\
\hline Indomethacin $(+$ salt depletion \pm UNX) & Rat & Complex, clin. relevant & CPN for all rat models & {$[65-69]$} \\
\hline Indomethacin + L-NAME & Rat & Medullary hypoxia & & \\
\hline Indomethacin + L-NAME & Mouse & pathomechanistic & High drug dose needed & {$[70,71]$} \\
\hline Water deprivation (dehydration) & & $\begin{array}{l}\text { Dehydration amplifies } \\
\text { injury }\end{array}$ & $\begin{array}{l}\text { Hydration state affects } \\
\text { CI-AKI progression }\end{array}$ & \\
\hline Dehydration (24 h) & Rat & & & {$[72,73]$} \\
\hline Dehydration (72 h) & Mouse, Rat & & & {$[35,74,75]$} \\
\hline Dehydration $(24 \mathrm{~h})+$ eNOS deficiency $(\mathrm{KO})$ & Mouse & & & {$[76]$} \\
\hline Dehydration $(24 \mathrm{~h})+$ Indomethacin + furosemide & Rat & & & {$[34]$} \\
\hline Dehydration $(24 \mathrm{~h})+$ glycerol rhabdomyolysis & Rat & & & {$[36,77-80]$} \\
\hline Surgical kidney injury models & & Reliable models & $\begin{array}{l}\text { Microsurgery } \\
\text { experience }\end{array}$ & \\
\hline Acute kidney injury (AKI) & & Short duration & Species differences & \\
\hline Ischemia-reperfusion & Mouse & & & [81] \\
\hline Chronic kidney disease (CKD) & & Clinical relevance & Chronic protocol & \\
\hline Diabetes (streptozotocin: STZ) & Rat & & & {$[82,83]$} \\
\hline $5 / 6$ nephrectomies + dehydration $(48 \mathrm{~h})$ & Rat & & & {$[84,85]$} \\
\hline Long term cholesterol feeding & Rat & & & [86] \\
\hline
\end{tabular}

clin.: clinically, UNX: Uninephrectomy, CPN: chronic progressive nephropathy, and eNOS: endothelial nitrogen monoxide synthase.

The classic rat model of CI-AKI includes inhibition of vasodilators with nitric oxide synthase (NOS) inhibition by $10 \mathrm{mg} / \mathrm{kg} \mathrm{N} \omega$-nitro-L-arginine methyl ester (L-NAME) combined with prostaglandin synthesis (cyclooxygenase (COX) enzyme) inhibition by $10 \mathrm{mg} / \mathrm{kg}$ indomethacin [67]. The NO + prostaglandin inhibition rat model was reproduced in mice by Lee et al. [70]. In C57BL/6J [personal communication] mice, treatment with $10 \mathrm{mg} / \mathrm{kg}$ L-NAME $+10 \mathrm{mg} / \mathrm{kg}$ indomethacin $+1 \mathrm{~g} / \mathrm{kg}$ iohexol (Omnipaque/viscosity: 11.2, osmolality: 780, Table 1) induced a tripling of plasma creatinine [70]. However, a more recent study by Linkermann et al. reported that in C57BL/6N mice (Charles River, Germany) unilateral nephrectomy + indomethacin $(100 \mu \mathrm{g} / \mathrm{kg})+\mathrm{L}-$ NAME $(100 \mu \mathrm{g} / \mathrm{kg})+$ water deprivation $(16 \mathrm{~h})+$ iomeprol (Imeron/viscosity: 8.1 , osmolality: 726 , Table 1) $(250 \mu \mathrm{L})$ did not induce any creatinine or urea elevation [81]. For a CI-AKI model the additional insults should not cause major renal injury. Higher doses $(>100 \mu \mathrm{g} / \mathrm{kg})$ of indomethacin with LNAME induced severe acute renal failure in Linkermann's studies and thus a CI-AKI model was not used [personal communication]. Finally, Linkermann and colleagues applied acute ischemia induced by 30 minutes of bilateral renal pedicle clamping + RCM $24 \mathrm{~h}$ after reperfusion as a CI-AKI mouse model [81]. This model provides a reliable method to induce CI-AKI; however it requests a staff experienced in microsurgical procedures. Mice are resistant to several human renal diseases contrary to rats [93]. The slightly lower viscosity and osmolality of iomeprol used by Linkermann et al. do not explain the observed difference between the 2 mouse studies. However, there are substantial genetic and phenotypic substrain differences [94] between C57BL/6J and $\mathrm{N}$ mice [95]. Also in renal disease models C57BL/6J mice were resistant to different kidney injuries, such as doxorubicin tubulopathy [96], obesity [97, 98], diet [99], or streptozotocin induced diabetic nephropathy [100] and hepatic, renal, and cardiac fibrosis [101]. In the background genetic differences have been demonstrated $[94,102,103]$. NIH-Swiss [104] or 129/SV [105] mice are even more resistant to renal ischemia-reperfusion injury than $\mathrm{C} 57 \mathrm{Bl} / 6$ mice. According to our comparison of J and N C57BL/ 6 mice, 24 hours after 30 min renal ischemia blood urea was $105 \pm 20 \mathrm{mg} / \mathrm{dL}$ in J versus $150 \pm 24 \mathrm{mg} / \mathrm{dL}$ 
in $\mathrm{N}$ mice. Thus, J mice may be less sensitive to renal insults, including hypoxic injury compared to $\mathrm{N}$ mice.

Taken together, it is easier to induce CI-AKI in rabbits (single injection of RCM without any additional injury) than in rats and the most severe additional injury is required in mice (Table 3 ). As the site of urine concentration is the medulla, which is also the site of hypoxic injury in CI-AKI, we hypothesize that high concentrating ability (Table 2) may protect the renal medulla from RCM-induced hypoxic damage in mice. A hypothetic mechanism of protection may be preconditioning to hypoxia by the energy demanding process of establishing the high osmotic gradient between tubular epithelial cells and the medullary interstitium.

\section{Characteristic Histopathological Changes in CI-AKI}

5.1. Tubular Vacuolization Is a Histological Marker of CI-AKI. Iodinated contrast media are eliminated almost entirely by glomerular filtration [106]. Filtered RCM becomes concentrated in renal tubules during the concentration process of the primary urine. Thus, tubular epithelial cells are exposed to an increasing concentration of RCM. Consequently, tubular epithelial cell damage should be a leading histopathological event in CI-AKI [25].

A general histopathological feature of CI-AKI is vacuolization of tubular epithelial cells [42] (Figures 3(a) and 3(b)). Tubular vacuolization is commonly interpreted as a sign of drug toxicity [107]. A single injection of RCM to intact rats induced tubular vacuolization in the absence of other kidney pathologies [72, 90, 91]. Ultrastructural studies of these kidneys suggested that the vacuoles were membranebound lysosomes $[42,65,90]$. Although in one study vacuoles were absent if the CT contrast gadolinium DTPA was used, a more recent study did not confirm the absence of vacuoles by CT contrast materials [106]. These reversible, lysosomal alterations primarily detected in the proximal tubules are the earliest signs of RCM toxicity [72].

\subsection{Tubular Vacuolization Does Not Correlate with Renal Fun-} ction. Vacuolization is often reversible even after extremely high dosages of RCM in rats $[86,106]$ and functional deterioration is absent or mild. In humans, both anuria without vacuolization and diffuse vacuolization without loss of renal functional have been described $[107,108]$. Furthermore, vacuolization was absent in rats despite $24 \mathrm{~h}$ water deprivation + nephron reduction + high doses of different RCM $[107,108]$ but was present in another study on rats deprived of water $24 \mathrm{~h}$ before RCM injection. Both studies used Wistar rats. The vacuolization almost disappeared 48 hours after application of iobitridol but not after iohexol [73].

Vacuolization does not correlate with renal function impairment because

(i) tubular vacuolization per see does not cause loss of renal function,

(ii) tubular vacuolization resolves spontaneously, (iii) more severe tubular damage may lead to the shedding of vacuolated cells into the urinary space. New cells replace the shed epithelial cells.

This discrepancy between functional and morphological deterioration poses a problem for the histopathological evaluation. Optimally, CI-AKI histopathology should be evaluated within 24-72 hours after induction and a serial evaluation is better than choosing only one time-point.

\subsubsection{Possible Other Causes of Tubular Vacuolization}

(1) Physiological Finding or Artifact. Vacuolization can be a physiological finding. In the human kidney, $70 \%$ of the juxtaglomerular cells contain vacuoles mostly in the perinuclear area, commonly seen by light microscopy. In mice, vacuolization is a common background finding in cortical epithelium [109] that can indicate a fixation artifact or postmortem changes [110]. Vacuolization is related to autolysis or poor fixation and is often observed in survival studies in animals sacrificed in a moribund state [62].

Vacuolization can be strain or sex dependent as well. In 2$3 \%$ of CD-1 mice lysosomal vacuoles were demonstrated [111]. Vacuoles were present only in male but not female SpragueDawley (SD) and Wistar-Han (WH) rats [62].

(2) Hydropic Vacuolization ("Osmotic Nephrosis"). Tubular vacuolization or hydropic degeneration [112] is a histological sign of the so-called "osmotic nephrosis." The name "osmotic nephrosis" comes from the initial description by Allen in 1951. He observed large vacuoles in tubular epithelial cells following hypertonic sucrose infusion in rabbits [113] and humans $[114,115]$ and interpreted the vacuolization as the result of an osmotic gradient between the tubular lumen and tubular cells [116]. Hydropic vacuolization develops after intravenous injection of substances eliminated by the kidney, such as RCM [72, 114], polyethylene-glycol- (PEG-) conjugated proteins [117], hydroxy-ethyl-starch (HES) [118-120], dextran $[121,122]$, sucrose [43], mannitol [123], glucose [124], glycerol [125], sorbitol [126], inulin [127], or sugar (sucrose [128130] or maltose [131]) stabilized intravenous immunoglobulin (IVIG) solutions. According to our experience (Figures 3(c) and $3(\mathrm{~d})$ ) different concentrations and repeated intraperitoneal doses of sucrose or maltose induced tubular vacuolization dose dependently. Sucrose-stabilized IVIG had a similar effect [32].

Although the condition was named after the swelling of tubular epithelial cells, the reason for this swelling is not osmotic pressure but the formation of vacuoles [114]. Ultrastructural studies demonstrated that the vacuoles are lysosomes. The agents causing hydropic vacuolization are taken up by tubular epithelial cells through pinocytosis [107, 108] already $5 \mathrm{~min}$ after injection and appear as small vesicles on electron microscopy [72]. Pinocytotic vesicles fuse together and fuse with lysosomes forming the larger vacuoles, detectable by light microscopy $[114,132]$. Thus, there is consensus about the rejection of the osmotic hypothesis [106-108], but the misleading term [107] is still in use [114].

Hydropic vacuolization is reversible [43] and renal function loss is often missing $[32,43,117]$. Initially fine apical 


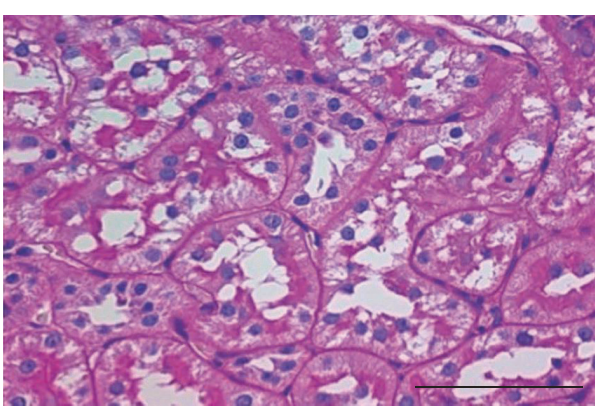

(a)

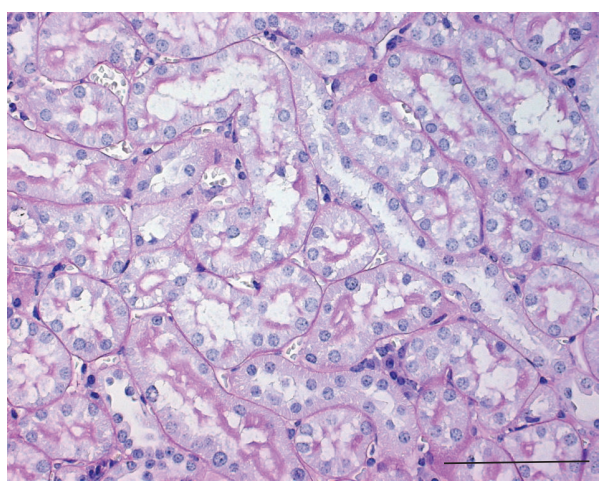

(c)

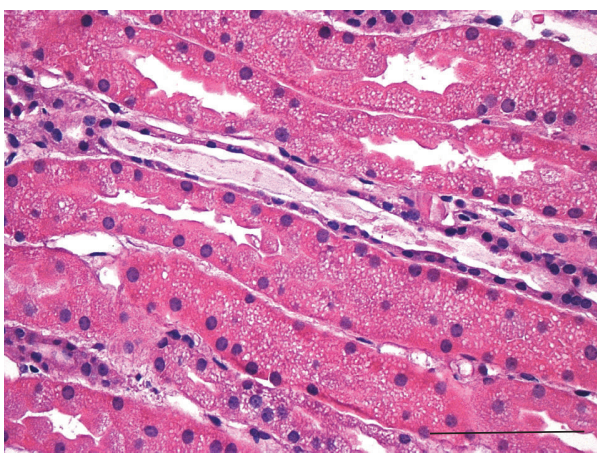

(e)

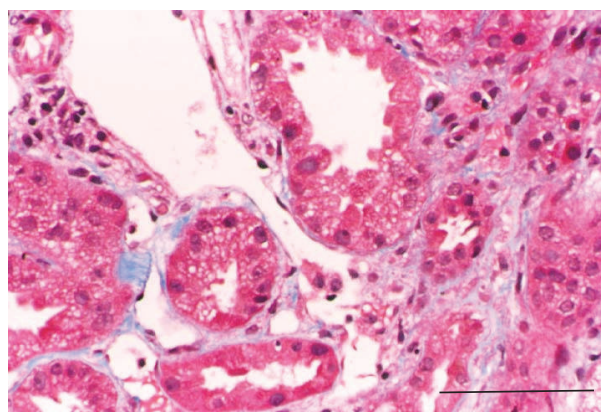

(g)

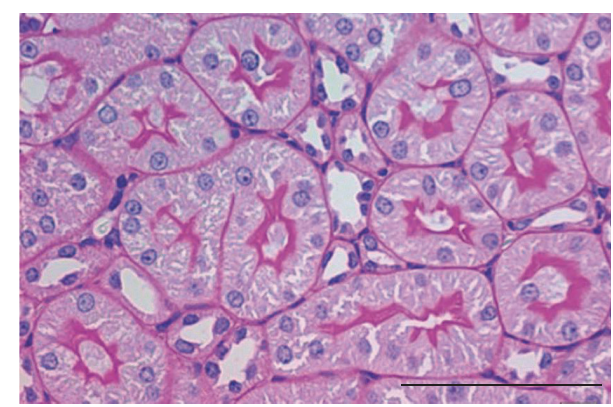

(b)

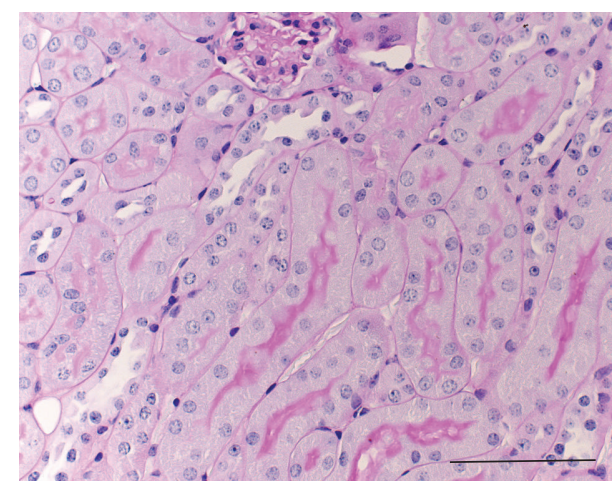

(d)

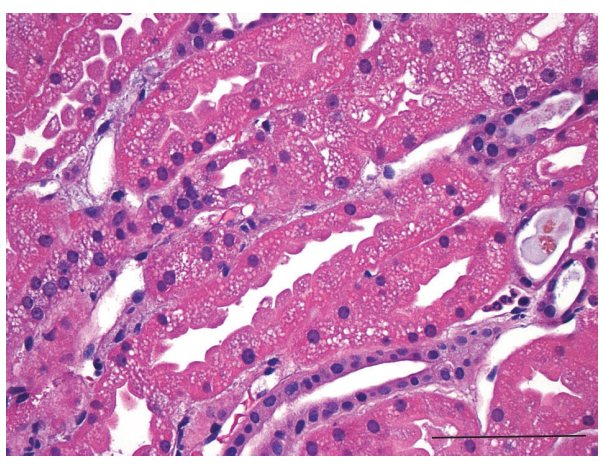

(f)

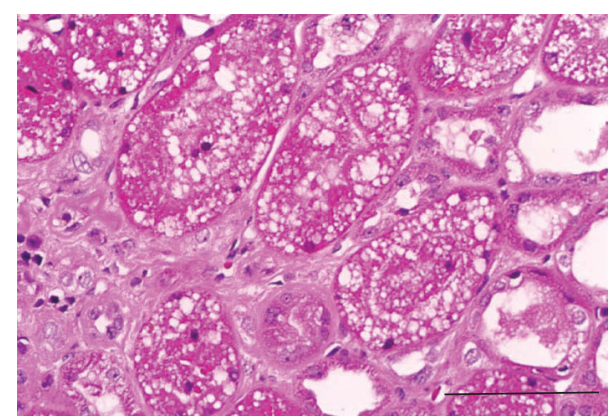

(h)

FIGURE 3: Vacuolization in different rodent models of CI-AKI. $(a, b)$ Tubular cell vacuolization in a CI-AKI rat (Sprague-Dawley) model. (a) Indomethacin + L-NAME + ioversol. (b) Normal rat kidney cortex (PAS, 400x, [31]). (c, d) Hydropic degeneration in mice. (c) Sucroseinduced hydropic degeneration of tubular cells in mouse (NMRI mouse, three ip. injections of 5\% sucrose). (d) Normal histology of an intact mouse (PAS, 400x, [32]). (e-h) Vacuolization induced by calcineurin toxicity versus ischemia. (e-g) Isometric vacuolization in calcineurin inhibitor (CNI) toxicity (courtesy of Professor Michael A. Nalesnik, MD, University of Pittsburg, Division of Transplantation Pathology). (h) Coarse, irregular vacuolization following ischemia (HE, 400x, (h) from [33], with permission). Scale bar represents $100 \mu \mathrm{m}$. 
vesicles become large by fusion and dislocate the nucleus at advanced stages, which can be accompanied by functional deterioration. N-Acetyl- $\beta$-D-glucosaminidase (NAG) and lactate dehydrogenase $(\mathrm{LDH})$ are damage markers of proximal tubular epithelial cells [133-135]. RCM injection induced a dose-dependent vacuolization with an increase in urinary NAG and LDH excretion that correlated with vacuolization suggesting a pathophysiological role for vacuoles in CI-AKI [106].

Osmotic diuresis (e.g., induced by mannitol) has been even suggested as a protective mechanism against CI-AKI by accelerating elimination of the contrast material from the tubular lumen [136]. Our experience in mice did not support any beneficial effects of mannitol. In a mouse model, 22minute renal ischemia + Omnipaque $(8 \mathrm{~mL} / \mathrm{kg})$ was followed by a $3.2 \%$ mannitol infusion at $12 \mathrm{~mL} / \mathrm{kg}$ per hour but did not provide any functional (urea retention, NGAL excretion) or morphological protection against CI-AKI (unpublished). Similarly, a recent meta-analysis concluded that intravenous mannitol did not have additional benefits over hydration in AKI patients and mannitol was even detrimental in CI-AKI patients [137].

(3) Further Causes of Tubular Vacuolization. A special form of tubular epithelial cell vacuolization is phospholipidosis (PLD): a reversible accumulation of polar phospholipids in different organs such as the kidney, liver, lung, brain, and lymphoid tissues [91]. PLD can be caused by certain drugs (such as antibiotics (e.g., aminoglycosides [138]) or tricyclic antidepressants). These cationic drugs accumulate in lysosomes [72, 91]. The morphological hallmark in PLD is the lamellar structure of the lysosomes (lamellar bodies). Functional deterioration is usually absent in PLD [125] as it is in other forms of hydropic vacuolization.

Calcineurin inhibitors (CNI) such as cyclosporine A (CsA) or tacrolimus (Tac) also cause vacuolization of tubular cells [107], which appear similar to the previous pathologies, although more isometric (Figures 3(e)-3(h)) [112, 114]. However, isometric vacuoles were described after RCM or mannitol administration as well $[107,139]$. The vacuoles in CNI toxicity are not lysosomes but are dilated endoplasmic reticulum due to immune mediated tubular injury [107] as verified by electron microscopy $[114,140]$. In contrast to the causes of tubular vacuolization described above, CNI toxicity is accompanied by loss of renal function [141] due to renal vascular injury and/or thrombotic microangiopathy.

5.2.2. Pathomechanism of Contrast-Induced Tubular Vacuolization. CI-AKI vacuoles were located primarily in the proximal tubules and are lysosomes [44, 142]. Iodine was retained in the renal cortex [44] and the RCM was abundant in vacuoles 7 days $[143,144]$ and was still present 28 days [143] after administration, besides normal renal function $[44,144]$. Thus, CI-AKI vacuoles are a consequence of RCM reabsorption.

Despite high RCM doses, vacuoles were absent in healthy kidneys and no tubular necrosis or atrophy developed unless there was some concomitant or predisposing renal damage
[108]. RCM induced AKI in transplanted kidneys during an acute rejection episode but not during a rejection-free period [108]. Functional impairment can be absent as long as proximal tubular vacuolization may be within the kidney's functional reserve capacity [144]. The duration of vacuoles' presence depends on the digestibility of the pinocytosed substance $[114,132]$. Preexisting (e.g., hypoxic or diabetic) kidney damage can substantially delay lysosomal digestion [114] and, thus, prolong the presence of the vacuoles.

In summary, tubular vacuolization is a consequence of pinocytosis of the RCM and lysosomal fusion. Tubular vacuolization is an early sign of CI-AKI but without comorbidities it does not progress to tubular cell necrosis [114]. Although tubular vacuolization is a direct consequence of the RCM present in the tubular lumen, it is not specific-as several other pathologies can cause it and it is not sensitive-as there is little correlation with renal function [18]. Taken together, vacuolization is the earliest marker of CI-AKI. However, its lack of specificity, the lack of correlation with renal function, and its tendency to disappear prevent the use of tubular vacuolization as a sole hallmark of CI-AKI.

\section{Further Pathological Markers of CI-AKI}

6.1. Hypoxic Damage. It is generally accepted that hypoxia plays an important role in the development of CI-AKI [124]. In healthy rabbits, a single injection of RCM induced medullary hypoxia due to reduction of renal blood flow (RBF) as demonstrated by magnetic resonance studies [145-148]. Already in the 70s it has been described that RCM injection was associated with a $30-50 \%$ decline of para-aminohippurate $(\mathrm{PAH})$ extraction in dogs $[149,150]$ and humans [151] suggesting a reduction in $\operatorname{RBF}[18,149]$. Measurements with electromagnetic flow meters allowed a more detailed analysis and demonstrated an initial transient $(<30 \mathrm{sec})$ vasodilation before the prolonged (5-15 $\mathrm{min}$ ) vasoconstriction [152] with substantial decrease in RBF and glomerular filtration (GFR). Vasoconstriction of peritubular capillaries causes prolonged medullary hypoxia [21, 146-148, 152]. However, the mechanism of vasoconstriction is not clear. Previous theories about osmotic injury or high viscosity are not supported by recent studies. Similarly, a central role of the reninangiotensin-aldosterone system (RAAS) is not supported by the facts that the decrease in RBF preceded the increase in plasma renin activity (PRA) and angiotensin-II antagonists did not inhibit the RCM-induced vasoconstriction $[46,152]$. On the other hand, nitric oxide and prostanoids protect from RCM-induced vasoconstriction [67]. Inhibition of these systems is often used in CI-AKI models $[65,66,68,69]$. Thus, reduction of dilator prostanoids and the $\mathrm{NO}$ system may be involved in RCM-induced medullary hypoxia.

6.1.1. Endothelial Damage. The contribution of reactive oxygen species (ROS) to CI-AKI pathology is widely accepted. ROS contribute to intrarenal vasoconstriction by scavenging NO. Endothelin also contributes to the vasoconstriction [20]. Vascular endothelial injury has been suggested in the background of contrast-induced vasoconstriction [25]. The 
endothelial cells are the first to come in contact with intravenously injected RCM [25]. Direct endothelial cell damage was observed by electron microscopy in rat aortic endothelial cells [153]. Endothelial damage in peritubular capillaries by RCM directly or through ROS can be an important driving force of the medullary hypoxia.

6.2. Patchy Nature of Hypoxic Damage. Tubular epithelial cells are the most sensitive to hypoxia. However, there are substantial regional differences in the severity of hypoxia. As detailed below, there is an inverse relationship between oxygen supply and need from outer cortex to inner medulla. Furthermore, with increasing distance from vasa recta oxygenation is decreasing. Due to these regional differences of oxygen supply and demand, histological changes are often focal or patchy and inhomogeneous in the postischemic or CI-AKI kidney. This inhomogeneity may explain negative biopsy results despite severe functional deterioration in humans and point to the necessity of systemic evaluation of whole kidney cross sections in rodent experiments.

6.2.1. Tubular Hypoxia. Renal tubular epithelial cells are the most sensitive to hypoxia due to their high metabolic demand. Furthermore, due to the countercurrent circulatory system of the kidney, the oxygen supply decreases towards the medulla as the oxygen demand increases. Thus, tubular epithelial cells are the first to suffer from hypoxic damage. Despite many papers describing hypoxia as an important contributor to CI-AKI, tubular cell necrosis is usually absent, despite the presence of proximal tubule vacuolization [72, $106,154,155]$. RCM per see do not cause necrosis (Figures 4(a) and $4(\mathrm{~b}))$. Necrosis was present only if RCM was combined with other hypoxia triggers (Figures $4(\mathrm{c})$ and $4(\mathrm{~d})$ ). Thus, direct toxic injury of RCM to TEC is not likely in healthy kidneys; however, the primary targets of renal hypoxia are TEC; thus a hypoxic injury may sensitize TEC to RCM toxicity.

6.3. Tubular Toxicity. Direct tubular toxicity of RCM is considered to participate in the pathomechanism of CI-AKI [5, $14,156]$. However, most of the direct toxicity data are based on in vitro studies, reporting about reduced cell viability in animal [157-162] or human cell cultures [33, 163]. In suspended rabbit tubular epithelial cells [164] or isolated proximal tubule segments [165] RCM toxicity was observed only with concomitant ischemia [18]. Furthermore, in different tubular cell cultures RCM induced mitochondrial swelling [65] and DNA fragmentation and/or apoptosis [46, 163, 166169]. Also, in human CI-AKI patients, tubular cells were found in the urine [170]. However, incubation with RCM at therapeutic concentrations did not induce cell death, despite rapid uptake of RCM in cultured primary or immortalized tubular epithelial cells or isolated mouse tubules [81]. Therefore, the suggested mechanism of RCM-induced cytotoxicity in vivo [170] is apoptosis induced by oxidative damage to the tubular epithelial cell membrane by reactive oxygen species (ROS) [20].

\section{Further Histological Changes Related Primarily to the Model and Not to RCM Injection}

7.1. Ischemia-Reperfusion Injury Induced by Renal Clamping. Rodent CI-AKI models apply renal hypoxia to aggravate the kidney damage that is subclinical if RCM is given alone (Table 3). Although RCM alone does not cause necrosis, the addition of hypoxia culminates in acute tubular necrosis (ATN) (Figures 4(c) and 4(d)) [171].

In these models a control group with renal ischemia/ hypoxia but without RCM is necessary to differentiate the effects of RCM from clamping. The severity of ischemia/ hypoxia has to be adjusted as too severe damage may prohibit the evaluation of RCM-induced pathology, whereas if the model is too mild, kidneys may remain unaffected.

A disadvantage is the fundamental difference between rodent renal ischemia-reperfusion injury and human hypoxic AKI. Important differences include the following: complete cessation of blood flow (anoxia) in rodent models versus reduced blood flow (hypoxia) in humans, and temperature during the anoxia/hypoxia is close to physiologic in rodent models, whereas it is often reduced in human AKI. Warm ischemia primarily affects the cortex and the outer stripe, whereas cold ischemia damages the inner stripe and the renal papilla [171]. Our own observations confirm that in the mouse warm ischemia-reperfusion model cortex and outer stripe of the medulla are the primary localization of tubular injury [172] as opposed to papillary necrosis in several forms of human AKI (CI-AKI, non-steroid induced (analgesic) nephropathy or AKI accompanying prolonged surgery). The most affected outer stripe of the outer medulla in rodent models is much less developed in the human kidney [171].

In healthy (sham operated) kidneys tubules have narrow lumen in the cortex (Figure 4(a)) and intact brush border in the outer stripe (Figure 4(b)). Following 30 minutes of ischemia and $24 \mathrm{~h}$ reperfusion, tubuli in the cortex are dilated (Figure 4(c)) and filled with PAS positive hyaline in the outer stripe (Figure 4(g)) with loss of nuclei and cellular structure. On the other hand, cells of the inner stripe do not show morphologic damage (Figure 4(k)).

7.2. Ischemic-Injury Aggravated by Prostaglandin Inhibition (Indomethacin). A common pathomechanism in the nephrotoxicity of nonsteroidal anti-inflammatory drugs (NSAIDs, e.g., indomethacin, analgesic nephropathy), calcineurin inhibitor (CNI) immunosuppressives (CSA, Tac) (CNI nephropathy), and iodinated RCM (CI-AKI) is medullary hypoxia [173]. Dilator prostanoids serve as the last reserve for renal vasodilation [174] in injured kidneys such as in diabetic nephropathy or in a dehydrated state [82]. The suppression of prostanoids amplifies the medullary hypoxia both in CI-AKI and in analgesic nephropathy. In murine models of CI-AKI, with RCM and indomethacin, proximal tubular vacuolization is accompanied by medullary tubular necrosis and cast formation [20,65] (Figure 4(e)). Thus, the prostaglandin (and NOS) inhibition models have the advantage over renal clamping that they resemble more human CI-AKI pathology as the injury is located predominant to the renal medulla [171]. 


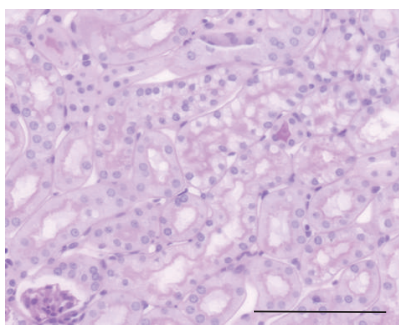

(a)

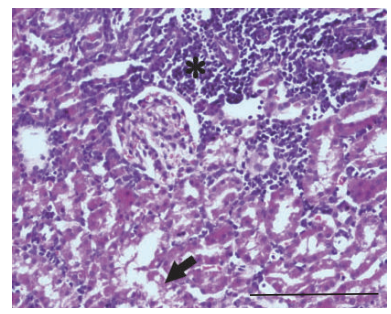

(e)

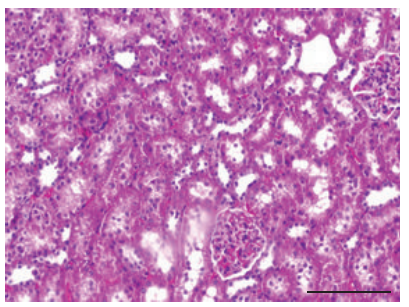

(i)

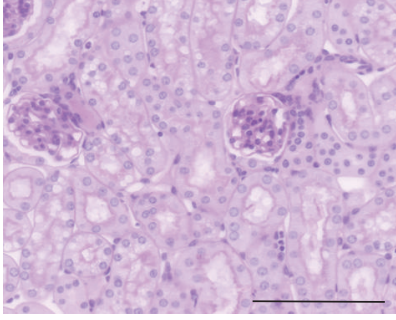

(b)

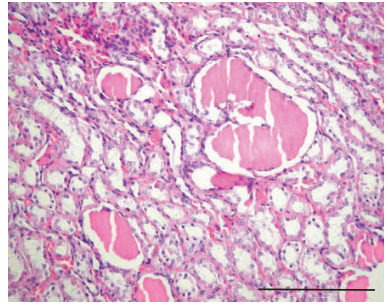

(f)

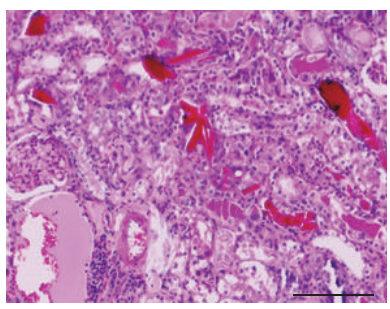

(j)

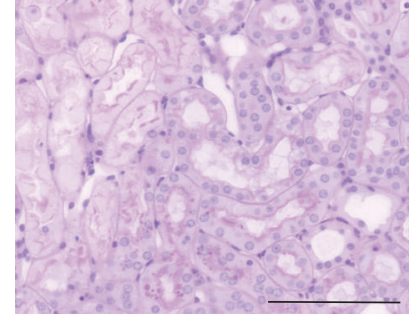

(c)

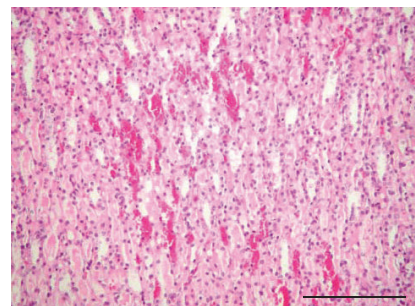

(g)

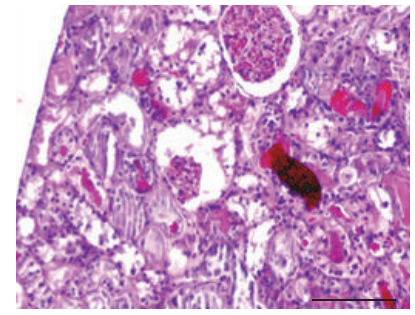

(k)

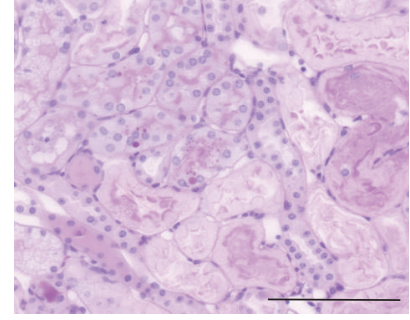

(d)

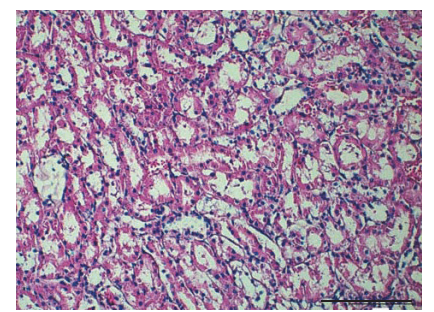

(h)

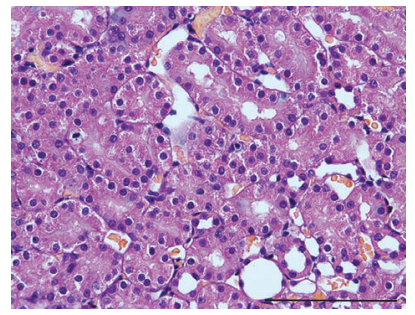

(l)

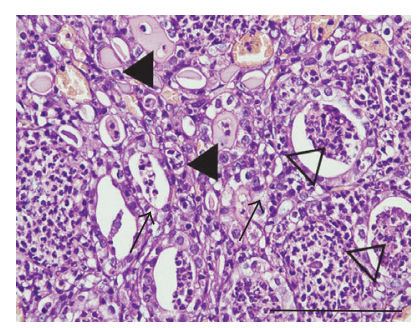

(m)

FIGURE 4: Histopathology of CI-AKI models with RCM administration and hypoxia. (a-d) RCM + renal ischemia mouse model (unpublished own data) (PAS, 400x). (a, b) Hypoxic tubular damage in mice $24 \mathrm{~h}$ after Omnipaque 350 iv. alone but no additional ischemia: besides vacuolization and mild tubular cell injury, no necrosis can be observed. Proximal tubuli have an intact brush border. (c, d) Ischemic changes in mice after $22 \mathrm{~min}$ ischemia + Omnipaque $350 \mathrm{iv}$. $24 \mathrm{~h}$ reperfusion: more severe tubular damage, flattening of tubular epithelial cells, loss of nuclei, dilation of tubular lumen, and cast formation demonstrate tubular necrosis. (e) RCM + indomethacin rat model. Necrotic tubular cells (arrow) and inflammatory cell infiltration (*). (RCM (10 mL/kg iomeprol), indomethacin (10 mg/kg), and HE, 200x, [34]) (f-h) $\mathrm{RCM}+$ dehydration rat model. Tubular casts (f, g), medullary congestion (g), and tubular necrosis (h) (72 h dehydration + RCM, HE, 200x, [35] with permission). (i-k) Glycerol based CI-AKI model. (i) Normal rat kidney. (j) Glycerol (im) + 24 h water deprivation. (k) Glycerol + RCM. Tubular necrosis and cast formation are more sever after combined injury (HE, 200x, from [36] with permission). (l, m) Combined model of diabetic nephropathy + RCM. (1) Tubular vacuolar degeneration (arrows), necrosis, hyaline casts (filled triangles), and cellular casts (hollow triangles) and inflammatory infiltration in contrast-treated diabetic and (m) normal rat kidney medulla (HE, 200x). From [37] with permission. Scale bar represents $100 \mu \mathrm{m}$.

7.3. Dehydration. Prolonged (72 h) dehydration combined with RCM causes CI-AKI in mice [75] and rats [35]. Dehydration alone significantly reduced renal cortical antioxidant (superoxide-dismutase [SOD] and catalase [CAT]) expression in rats [74]. The leading histopathological changes were tubular necrosis with cast formation and medullary vascular congestion (Figures 4(f)-4(h)) $[35,75]$.

7.4. Glycerol Induced Rhabdomyolysis. Intramuscular glycerol injection-induced rhabdomyolysis is a model of acute renal 
failure. As the hydration status of the body during rhabdomyolysis significantly influences the development of renal failure, 24-hour water deprivation precedes glycerol injection in this model [77]. Histological damage includes tubular necrosis: hyaline and hemorrhagic casts in cortex and medulla aggravated by the addition of RCM (Figures 4(i)$4(\mathrm{k}))[78]$.

7.5. Tubulointerstitial Fibrosis. CKD is an important risk factor for CI-AKI. Thus, CKD rodent models plus iv. RCM injection is also used to model CI-AKI [82, 84, 85, 175]. For example, RCM induces tubular necrosis in diabetic nephropathy kidneys (Figures 4(l) and 4(m)) [37]. A yes-or-no phenomenon regarding RCM dose has been reported in the diabetic CI-AKI model as $8 \mathrm{~mL} / \mathrm{kg}$ or $10 \mathrm{~mL} / \mathrm{kg}$ iopromide did not but 12 or $16 \mathrm{~mL} / \mathrm{kg}$ did induce renal functional decline $[9,37]$.

\section{Conclusion}

In summary, the most specific histopathological lesions in rodent CI-AKI models are vacuolization of tubular epithelial cells and medullary hypoxia. Necrosis is only present if other hypoxia triggers are also applied as part of the model. As histopathologic changes lack specificity it is a relevant marker but not sufficient enough. Thus, further functional parameters and molecular biomarkers should be included in CIAKI animal studies for a comprehensive analysis of disease progression. As the injection of RCM alone does not cause overt AKI in rodents, multiple insults are necessary for inducing histopathological and functional decline. The difference in sensitivity between species and the correlation with renal concentrating ability suggests that high concentrating ability may protect from CI-AKI.

\section{Competing Interests}

The authors have declared that no competing interests exist.

\section{Acknowledgments}

Support was provided to Péter Hamar from the Hungarian Research Fund: OTKA-ANN (FWF) 110810 and OTKA-SNN 114619. Péter Hamar acknowledges support from the Bolyai Research Scholarship of the Hungarian Academy of Sciences and the Merit Prize of the Semmelweis University.

\section{References}

[1] J. Schilp, C. de Blok, M. Langelaan, P. Spreeuwenberg, and C. Wagner, "Guideline adherence for identification and hydration of high-risk hospital patients for contrast-induced nephropathy," BMC Nephrology, vol. 15, article 2, 2014.

[2] U. Ludwig and F. Keller, "Prophylaxis of contrast-induced nephrotoxicity," BioMed Research International, vol. 2014, Article ID 308316, 8 pages, 2014.

[3] B. J. Barrett and P. S. Parfrey, "Clinical practice. Preventing nephropathy induced by contrast medium," The New England Journal of Medicine, vol. 354, no. 4, pp. 379-386, 2006.
[4] A. Ukaigwe, P. Karmacharya, M. Mahmood et al., "Meta-analysis on efficacy of statins for prevention of contrast-induced acute kidney injury in patients undergoing coronary angiography," American Journal of Cardiology, vol. 114, no. 9, pp. 12951302, 2014.

[5] R. Nicola, K. W. Shaqdan, K. Aran, M. Mansouri, A. Singh, and H. H. Abujudeh, "Contrast-induced nephropathy: identifying the risks, choosing the right agent, and reviewing effective prevention and management methods," Current Problems in Diagnostic Radiology, vol. 44, no. 6, pp. 501-504, 2015.

[6] V. Filiopoulos, D. Biblaki, and D. Vlassopoulos, "Neutrophil gelatinase-associated lipocalin (NGAL): a promising biomarker of contrast-induced nephropathy after computed tomography," Renal Failure, vol. 36, no. 6, pp. 979-986, 2014.

[7] J. J. Keaney, C. M. Hannon, and P. T. Murray, "Contrast-induced acute kidney injury: how much contrast is safe?" Nephrology Dialysis Transplantation, vol. 28, no. 6, pp. 1376-1383, 2013.

[8] N. M. A. Mohammed, A. Mahfouz, K. Achkar, I. M. Rafie, and R. Hajar, "Contrast-induced nephropathy," Heart Views, vol. 14, no. 3, pp. 106-116, 2013.

[9] N. Katsiki, V. G. Athyros, A. Karagiannis, and D. P. Mikhailidis, "Contrast-induced nephropathy: an 'all or none' phenomenon?” Angiology, vol. 66, no. 6, pp. 508-513, 2015.

[10] A. D. Calvin, S. Misra, and A. Pflueger, "Contrast-induced acute kidney injury and diabetic nephropathy," Nature Reviews Nephrology, vol. 6, no. 11, pp. 679-688, 2010.

[11] E. P. Pendergrass and G. W. Chamberlain, "A survey of death and unfavorable sequelae following the administration of contrast media," American College of Radiology, vol. 48, pp. 741-762, 1942.

[12] E. A. Merrill, Procedures in U.S. Hospitals 2003, Agency for Healthcare Research and Quality, Rockville, Md, USA, 2005.

[13] W. P. Burgess and P. J. Walker, "Mechanisms of contrast-induced nephropathy reduction for saline $(\mathrm{NaCl})$ and sodium bicarbonate $\left(\mathrm{NaHCO}_{3}\right)$," BioMed Research International, vol. 2014, Article ID 510385, 6 pages, 2014.

[14] M. Andreucci, T. Faga, A. Pisani, M. Sabbatini, D. Russo, and A. Michael, "Prevention of contrast-induced nephropathy through a knowledge of its pathogenesis and risk factors," Scientific World Journal, vol. 2014, Article ID 823169, 16 pages, 2014.

[15] T. H. Au, A. Bruckner, S. M. Mohiuddin, and D. E. Hilleman, "The prevention of contrast-induced nephropathy," Annals of Pharmacotherapy, vol. 48, no. 10, pp. 1332-1342, 2014.

[16] M. Naeem, G. E. McEnteggart, T. P. Murphy, E. Prince, S. Ahn, and G. Soares, "Fenoldopam for the prevention of contrastinduced nephropathy (CIN) - do we need more trials? A metaanalysis," Clinical Imaging, vol. 39, no. 5, pp. 759-764, 2015.

[17] D. Giacoppo, D. Capodanno, P. Capranzano, P. Aruta, and C. Tamburino, "Meta-analysis of randomized controlled trials of preprocedural statin administration for reducing contrastinduced acute kidney injury in patients undergoing coronary catheterization," American Journal of Cardiology, vol. 114, no. 4, pp. 541-548, 2014.

[18] A. S. Berns, "Nephrotoxicity of contrast media," Kidney International, vol. 36, no. 4, pp. 730-740, 1989.

[19] A. N. Pavlidis, D. A. Jones, A. Sirker, A. Mathur, and E. J. Smith, "Prevention of contrast-induced acute kidney injury after percutaneous coronary intervention for chronic total coronary occlusions," American Journal of Cardiology, vol. 115, no. 6, pp. 844-851, 2015. 
[20] J. Golshahi, H. Nasri, and M. Gharipour, "Contrast-induced nephropathy; a literature review," Journal of Nephropathology, vol. 3, no. 2, pp. 51-56, 2014.

[21] P. V. Prasad, A. Priatna, K. Spokes, and F. H. Epstein, “Changes in intrarenal oxygenation as evaluated by BOLD MRI in a rat kidney model for radiocontrast nephropathy," Journal of Magnetic Resonance Imaging, vol. 13, no. 5, pp. 744-747, 2001.

[22] L. Zhou and S. Duan, "Effects of angiotensin converting enzyme inhibitors and angiotensin receptor blockers in contrastinduced nephropathy," Kidney and Blood Pressure Research, vol. 38, no. 2-3, pp. 165-171, 2013.

[23] S. N. Heyman, C. Rosenberger, S. Rosen, and M. Khamaisi, "Why is diabetes mellitus a risk factor for contrast-induced nephropathy?" BioMed Research International, vol. 2013, Article ID 123589, 8 pages, 2013.

[24] P. Pattharanitima and A. Tasanarong, "Pharmacological strategies to prevent contrast-induced acute kidney injury," BioMed Research International, vol. 2014, Article ID 236930, 21 pages, 2014.

[25] M. Andreucci, T. Faga, A. Pisani, M. Sabbatini, and A. Michael, "Acute kidney injury by radiographic contrast media: pathogenesis and prevention," BioMed Research International, vol. 2014, Article ID 362725, 21 pages, 2014.

[26] W. Vandenberghe, W. De Corte, and E. A. J. Hoste, "Contrastassociated AKI in the critically ill: relevant or irrelevant?" Current Opinion in Critical Care, vol. 20, no. 6, pp. 596-605, 2014.

[27] S. Namasivayam, M. K. Kalra, W. E. Torres, and W. C. Small, "Adverse reactions to intravenous iodinated contrast media: a primer for radiologists," Emergency Radiology, vol. 12, no. 5, pp. 210-215, 2006.

[28] M. Burns, The US Market for Medical Imaging Contrast Media, Bio-Tech Systems, Las Vegas, Nev, USA, 2004.

[29] Radiopharmaceuticals: A Global Strategic Business Report, Global Industry Analysts, Inc, San Jose, Calif, USA, 2015.

[30] "Contrast Media/Contrast Agents Market by Product (Iodinated, Gadolinium, Barium, Microbubble), by Procedure (XRay/CT, MRI, Ultrasound), by Application (Radiology, Interventional Radiology, Interventional Cardiology) Global forecast to 2020," Markets and markets, 2015.

[31] A. Kodama, H. Watanabe, R. Tanaka et al., "A human serum albumin-thioredoxin fusion protein prevents experimental contrast-induced nephropathy," Kidney International, vol. 83, no. 3, pp. 446-454, 2013.

[32] Z. Racz, E. Nagy, L. Rosivall, J. Szebeni, and P. Hamar, "Sugarfree, glycine-stabilized intravenous immunoglobulin prevents skin but not renal disease in the MRL/lpr mouse model of systemic lupus," Lupus, vol. 19, no. 5, pp. 599-612, 2010.

[33] M. Andreucci, G. Fuiano, P. Presta et al., "Radiocontrast media cause dephosphorylation of Akt and downstream signaling targets in human renal proximal tubular cells," Biochemical Pharmacology, vol. 72, no. 10, pp. 1334-1342, 2006.

[34] M. Buyuklu, F. M. Kandemir, M. Ozkaraca et al., "Benefical effects of lycopene against contrast medium-induced oxidative stress, inflammation, autophagy, and apoptosis in rat kidney," Human and Experimental Toxicology, vol. 34, no. 5, pp. 487-496, 2015.

[35] O. Toprak, M. Cirit, M. Tanrisev et al., "Preventive effect of nebivolol on contrast-induced nephropathy in rats," Nephrology Dialysis Transplantation, vol. 23, no. 3, pp. 853-859, 2008.
[36] M. Saritemur, H. Un, E. Cadirci et al., "Tnf- $\alpha$ inhibition by infliximab as a new target for the prevention of glycerol-contrast-induced nephropathy," Environmental Toxicology and Pharmacology, vol. 39, no. 2, pp. 577-588, 2015.

[37] J. Su, W. Zou, W. Cai et al., "Atorvastatin ameliorates contrast medium-induced renal tubular cell apoptosis in diabetic rats via suppression of Rho-kinase pathway," European Journal of Pharmacology, vol. 723, no. 1, pp. 15-22, 2014.

[38] P. D. Jacobson and C. J. Rosenquist, "The introduction of lowosmolar contrast agents in radiology. Medical, economic, legal, and public policy issues," The Journal of the American Medical Association, vol. 260, no. 11, pp. 1586-1592, 1988.

[39] A. M. Bucher, C. N. De Cecco, U. J. Schoepf et al., "Is contrast medium osmolality a causal factor for contrast-induced nephropathy?" BioMed Research International, vol. 2014, Article ID 931413, 8 pages, 2014.

[40] G. Biondi-Zoccai, M. Lotrionte, H. S. Thomsen et al., "Nephropathy after administration of iso-osmolar and low-osmolar contrast media: evidence from a network meta-analysis," International Journal of Cardiology, vol. 172, no. 2, pp. 375-380, 2014.

[41] R. D. Moore, E. P. Steinberg, N. R. Powe et al., "Nephrotoxicity of high-osmolality versus low-osmolality contrast media: randomized clinical trial," Radiology, vol. 182, no. 3, pp. 649-655, 1992.

[42] J. C. Jennette, V. D. D’Agati, J. L. Olson, and F. G. Silva, Heptinstall's Pathology of the Kidney, Edited by V. D. D. A. Charles Jennette, J. L. Olson and F. G. Silva, Wolters Kluwer, 7th edition, 2014.

[43] A. J. Monserrat and A. E. Chandler, "Effects of repeated injections of sucrose on the kidney. Histologic, cytochemical and functional studies in an animal model," Virchows Archiv B: Cell Pathology, vol. 19, no. 1, pp. 77-91, 1975.

[44] G. Jost, H. Pietsch, J. Sommer et al., "Retention of iodine and expression of biomarkers for renal damage in the kidney after application of iodinated contrast media in rats," Investigative Radiology, vol. 44, no. 2, pp. 114-123, 2009.

[45] E. Seeliger, M. Sendeski, C. S. Rihal, and P. B. Persson, "Contrast-induced kidney injury: mechanisms, risk factors, and prevention," European Heart Journal, vol. 33, no. 16, pp. 2007-2015, 2012.

[46] P. B. Persson, P. Hansell, and P. Liss, "Pathophysiology of contrast medium-induced nephropathy," Kidney International, vol. 68, no. 1, pp. 14-22, 2005.

[47] J. Ueda, A. Nygren, P. Hansell, and U. Erikson, "Influence of contrast media on single nephron glomerular filtration rate in rat kidney: a comparison between diatrizoate, iohexol, ioxaglate, and iotrolan," Acta Radiologica, vol. 33, no. 6, pp. 596-599, 1992.

[48] J. Edgren, L. Laasonen, P.-H. Groop, and L. Groop, "Iohexol and metrizoate in urography of insulin dependent patients," Acta Radiologica, vol. 27, no. 3, pp. 265-267, 1986.

[49] Å. Billström, S.-O. Hietala, F. Lithner, J. Merikanto, M. Wirell, and S. Wirell, "Nephrotoxicity of contrast media in patients with diabetes mellitus. A comparative urographic and angiographic study with iohexol and metrizoate," Acta Radiologica, vol. 30, no. 5, pp. 509-515, 1989.

[50] C. Tornquist and S. Holtas, "Renal angiography with iohexol and metrizoate," Radiology, vol. 150, no. 2, pp. 331-334, 1984.

[51] R. Solomon, "Contrast media: are there differences in nephrotoxicity among contrast media?" BioMed Research International, vol. 2014, Article ID 934947, 8 pages, 2014. 
[52] P. M. Treuting, S. M. Dintzis, W. F. Charles, H. D. Liggitt, and K. S. Montine, Comparative Anatomy and Histology: A Mouse and Human Atlas, Elsevier/Academic Press, Boston, Mass, USA, 1st edition, 2012.

[53] L. Cullen-McEwen, M. R. Sutherland, and M. J. Black, "The human kidney, parallels in structure, spatial development, and timing of nephrogenesis," in Kidney Development, Disease, Repair and Regeneration, L. Mh, Ed., pp. 27-37, Elsevier, Academic Press, 2015.

[54] M. A. Zimanyi, J. F. Bertram, and M. J. Black, "Nephron number and blood pressure in rat offspring with maternal high-protein diet," Pediatric Nephrology, vol. 17, no. 12, pp. 1000-1004, 2002.

[55] I. J. Murawski, R. W. Maina, and I. R. Gupta, "The relationship between nephron number, kidney size and body weight in two inbred mouse strains," Organogenesis, vol. 6, no. 3, pp. 189-194, 2010.

[56] J. M. Sands and H. E. Layton, "The physiology of urinary concentration: an update," Seminars in Nephrology, vol. 29, no. 3, pp. 178-195, 2009.

[57] J. S. Finlayson and C. A. Baumann, "Mouse proteinuria," The American Journal of Physiology, vol. 192, no. 1, pp. 69-72, 1958.

[58] "Proteinuria in rats and mice," Nutrition Reviews, vol. 16, no. 11, pp. 337-340, 1958.

[59] J. M. Alt, H. Hackbarth, F. Deerberg, and H. Stolte, "Proteinuria in rats in relation to age-dependent renal changes," Laboratory Animals, vol. 14, no. 2, pp. 95-101, 1980.

[60] G. C. Hard and K. N. Khan, "A contemporary overview of chronic progressive nephropathy in the laboratory rat, and its significance for human risk assessment," Toxicologic Pathology, vol. 32, no. 2, pp. 171-180, 2004.

[61] C. F. Pinto, M. Watanabe, and M. D. F. F. Vattimo, "Hydration and $\mathrm{N}$-acetylcysteine in acute renal failure caused by iodinated contrast medium: an experiment with rats," Journal of Nephrology, vol. 21, no. 5, pp. 783-788, 2008.

[62] K. N. M. Khan and C. L. Alden, "Kidney," in Handbook of Toxicologic Pathology, W. M. Haschek, C. G. Rousseaux, and M. A. Wallig, Eds., pp. 1668-1724, Academic Press, San Diego, Calif, USA, 2001.

[63] V. Thongboonkerd, Renal and Urinary Proteomics: Methods and Protocols, Verlag GmbH \& Co, 2010.

[64] J. B. Hook and R. S. Goldstein, Toxicology of the Kidney, Edited by J. B. Hook and R. S. Goldstein, Raven Press, New York, NY, USA, 2nd edition, 1993.

[65] S. N. Heyman, M. Brezis, C. A. Reubinoff et al., "Acute renal failure with selective medullary injury in the rat," Journal of Clinical Investigation, vol. 82, no. 2, pp. 401-412, 1988.

[66] S. N. Heyman, M. Brezis, F. H. Epstein, K. Spokes, P. Silva, and S. Rosen, "Early renal medullary hypoxic injury from radiocontrast and indomethacin," Kidney International, vol. 40, no. 4, pp. 632-642, 1991.

[67] Y. Agmon, H. Peleg, Z. Greenfeld, S. Rosen, and M. Brezis, "Nitric oxide and prostanoids protect the renal outer medulla from radiocontrast toxicity in the rat," The Journal of Clinical Investigation, vol. 94, no. 3, pp. 1069-1075, 1994.

[68] Y. Yokomaku, T. Sugimoto, S. Kume et al., "Asialoerythropoietin prevents contrast-induced nephropathy," Journal of the American Society of Nephrology, vol. 19, no. 2, pp. 321-328, 2008.

[69] E. Ari, Y. Yilmaz, A. E. Kedrah et al., "Protective effect of the vasopressin agonist terlipressin in a rat model of contrastinduced nephropathy," American Journal of Nephrology, vol. 33, no. 3, pp. 269-276, 2011.
[70] H. T. Lee, M. Jan, C. B. Soo et al., "A1 adenosine receptor knockout mice are protected against acute radiocontrast nephropathy in vivo," American Journal of Physiology-Renal Physiology, vol. 290, no. 6, pp. F1367-F1375, 2006.

[71] L. Yao, H. Dong, C. X. Zhao et al., "Evaluation of urine fibrinogen level in a murine model of contrast-induced nephropathy," Vascular, vol. 24, no. 3, pp. 273-278, 2016.

[72] P. Tervahartiala, L. Kivisaari, R. Kivisaari, I. Virtanen, and C.G. Standertskjöld-Nordenstam, "Contrast media-induced renal tubular vacuolization: a light and electron microscopic study on rat kidneys," Investigative Radiology, vol. 26, no. 10, pp. 882-887, 1991.

[73] P. Tervahartiala, L. Kivisaari, R. Kivisaari, T. Vehmas, and I. Virtanen, "Structural changes in the renal proximal tubular cells induced by iodinated contrast media. Studies in dehydrated rats," Nephron, vol. 76, no. 1, pp. 96-102, 1997.

[74] T. Yoshioka, A. Fogo, and J. K. Beckman, "Reduced activity of antioxidant enzymes underlies contrast media-induced renal injury in volume depletion," Kidney International, vol. 41, no. 4, pp. 1008-1015, 1992.

[75] G. Schley, N. Cordasic, B. Klanke et al., Radiocontrast Nephropathy: Role of Endothelial Injury, and Chronic Consequences, ASN, Atlanta, Ga, USA, 2013.

[76] A. Khan, J. L. Maderdrut, M. Li et al., "Pituitary adenylate cyclase-activating polypeptide prevents contrast-induced nephropathy in a novel mouse model," Physiological Reports, vol. 1, no. 6, article e00163, 2013.

[77] Y. Zurovsky, "Models of glycerol-induced acute renal failure in rats," Journal of Basic and Clinical Physiology and Pharmacology, vol. 4, no. 3, pp. 213-228, 2011.

[78] S. B. Duan, Y. H. Wang, F. Y. Liu et al., "The protective role of telmisartan against nephrotoxicity induced by X-ray contrast media in rat model," Acta Radiologica, vol. 50, no. 7, pp. 754759, 2009.

[79] K. E. Al-Otaibi, A. M. Al Elaiwi, M. Tariq, and A. K. AlAsmari, "Simvastatin attenuates contrast-induced nephropathy through modulation of oxidative stress, proinflammatory myeloperoxidase, and nitric oxide," Oxidative Medicine and Cellular Longevity, vol. 2012, Article ID 831748, 8 pages, 2012.

[80] S.-B. Duan, F.-Y. Liu, J.-A. Luo et al., "Nephrotoxicity of highand low-osmolar contrast media: the protective role of amlodipine in a rat model," Acta Radiologica, vol. 41, no. 5, pp. 503-507, 2000.

[81] A. Linkermann, J. O. Heller, A. Prokai et al., “The RIP1-kinase inhibitor necrostatin-1 prevents osmotic nephrosis and contrast-induced AKI in mice," Journal of the American Society of Nephrology, vol. 24, no. 10, pp. 1545-1557, 2013.

[82] G.-H. Kim, "Renal effects of prostaglandins and cyclooxygenase-2 inhibitors," Electrolyte and Blood Pressure, vol. 6, no. 1, pp. 35-41, 2008.

[83] J. Deng, G. Wu, C. Yang, Y. Li, Q. Jing, and Y. Han, "Rosuvastatin attenuates contrast-induced nephropathy through modulation of nitric oxide, inflammatory responses, oxidative stress and apoptosis in diabetic male rats," Journal of Translational Medicine, vol. 13, no. 1, article 53, 2015.

[84] T.-Q. Liu, W.-L. Luo, X. Tan et al., "A novel contrast-induced acute kidney injury model based on the 5/6-nephrectomy rat and nephrotoxicological evaluation of iohexol and iodixanol in vivo," Oxidative Medicine and Cellular Longevity, vol. 2014, Article ID 427560, 14 pages, 2014.

[85] T. Liu, Y. Fang, S. Liu et al., "Limb ischemic preconditioning protects against contrast-induced acute kidney injury in rats 
via phosphorylation of GSK-3 $\beta$," Free Radical Biology and Medicine, vol. 81, pp. 170-182, 2015.

[86] S.-K. Yang, S.-B. Duan, P. Pan, X.-Q. Xu, N. Liu, and J. Xu, "Preventive effect of pentoxifylline on contrast-induced acute kidney injury in hypercholesterolemic rats," Experimental and Therapeutic Medicine, vol. 9, no. 2, pp. 384-388, 2015.

[87] D. A. Lauver, E. G. Carey, I. L. Bergin, B. R. Lucchesi, and H. S. Gurm, "Sildenafil citrate for prophylaxis of nephropathy in an animal model of contrast-induced acute kidney injury," PLoS ONE, vol. 9, no. 11, Article ID el13598, 2014.

[88] G. Pettersson, R. Towart, D. Grant, K. Thyberg, and K. Golman, "The rabbit renal toxicity test: a sensitive in vivo test for the nephrotoxicity of contrast agents," Academic Radiology, vol. 9, no. 1, pp. S62-S64, 2002.

[89] S. N. Heyman, S. Rosen, and C. Rosenberger, "Renal parenchymal hypoxia, hypoxia adaptation, and the pathogenesis of radiocontrast nephropathy," Clinical Journal of the American Society of Nephrology, vol. 3, no. 1, pp. 288-296, 2008.

[90] J. A. Rees, S. L. Old, and P. C. Rowlands, "An ultrastructural histochemistry and light microscopy study of the early development of renal proximal tubular vacuolation after a single administration of the contrast enhancement medium 'Iotrolan,"' Toxicologic Pathology, vol. 25, no. 2, pp. 158-164, 1997.

[91] Z. Ruben, D. C. Dodd, K. J. Rorig, and S. N. Anderson, "Disobutamide: a model agent for investigating intracellular drug storage," Toxicology and Applied Pharmacology, vol. 97, no. 1, pp. 57-71, 1989.

[92] L. Yao, G. K. Kolluru, K. G. Christopher, and W. W. Zhang, "The gene expression of adenosine receptors in the processes of contrast induced nephropathy in mouse kidney," Journal of Vascular Surgery, vol. 57, no. 5, pp. 80S-81S, 2013.

[93] G. J. Becker and T. D. Hewitson, "Animal models of chronic kidney disease: useful but not perfect," Nephrology Dialysis Transplantation, vol. 28, no. 10, pp. 2432-2438, 2013.

[94] K. Mekada, K. Abe, A. Murakami et al., "Genetic differences among C57BL/6 substrains," Experimental Animals, vol. 58, no. 2, pp. 141-149, 2009.

[95] C. Kiselycznyk and A. Holmes, "All (C57BL/6) mice are not created equal," Frontiers in Neuroscience, vol. 5, Article ID 10, p. 10, 2011.

[96] Z. Zheng, K. M. Schmidt-Ott, S. Chua et al., "A Mendelian locus on chromosome 16 determines susceptibility to doxorubicin nephropathy in the mouse," Proceedings of the National Academy of Sciences of the United States of America, vol. 102, no. 7, pp. 2502-2507, 2005.

[97] M. Kern, A. Knigge, J. T. Heiker et al., "C57BL/6JRj mice are protected against diet induced obesity (DIO)," Biochemical and Biophysical Research Communications, vol. 417, no. 2, pp. 717720, 2012.

[98] J. T. Heiker, A. Kunath, J. Kosacka et al., "Identification of genetic loci associated with different responses to high-fat dietinduced obesity in C57BL/6N and C57BL/6J substrains," Physiological Genomics, vol. 46, no. 11, pp. 377-384, 2014.

[99] E. Rendina-Ruedy, K. D. Hembree, A. Sasaki et al., "A comparative study of the metabolic and skeletal response of C57BL/6J and C57BL/6N mice in a diet-induced model of type 2 diabetes," Journal of Nutrition and Metabolism, vol. 2015, Article ID 758080, 13 pages, 2015.

[100] Z. Qi, H. Fujita, J. Jin et al., "Characterization of susceptibility of inbred mouse strains to diabetic nephropathy," Diabetes, vol. 54, no. 9, pp. 2628-2637, 2005.
[101] L. Walkin, S. E. Herrick, A. Summers et al., "The role of mouse strain differences in the susceptibility to fibrosis: a systematic review," Fibrogenesis and Tissue Repair, vol. 6, no. 1, article 18, 2013.

[102] E. Zurita, M. Chagoyen, M. Cantero et al., "Genetic polymorphisms among C57BL/6 mouse inbred strains," Transgenic Research, vol. 20, no. 3, pp. 481-489, 2011.

[103] C. D. Bryant, "The blessings and curses of C57BL/6 substrains in mouse genetic studies," Annals of the New York Academy of Sciences, vol. 1245, no. 1, pp. 31-33, 2011.

[104] M. J. Burne, M. Haq, H. Matsuse, S. Mohapatra, and H. Rabb, "Genetic susceptibility to renal ischemia reperfusion injury revealed in a murine model," Transplantation, vol. 69, no. 5, pp. 1023-1025, 2000.

[105] X. Lu, N. Li, N. Shushakova et al., "C57BL/6 and 129/SV mice: genetic difference to renal ischemia-reperfusion," Journal of Nephrology, vol. 25, no. 5, pp. 738-743, 2012.

[106] E. S. Harpur, D. Worah, P.-A. Hals, E. Holtz, K. Furuhama, and H. Nomura, "Preclinical safety assessment and pharmacokinetics of gadodiamide injection, a new magnetic resonance imaging contrast agent," Investigative Radiology, vol. 28, supplement 1, pp. S28-S43, 1993.

[107] P. S. Randhawa, R. S. Saad, M. Jordan, V. Scantlebury, C. Vivas, and R. Shapiro, "Clinical significance of renal biopsies showing concurrent acute rejection and tacrolimus-associated tubular vacuolization," Transplantation, vol. 67, no. 1, pp. 85-89, 1999.

[108] J.-F. Moreau, D. Droz, L.-H. Noel, J. Leibowitch, P. Jungers, and J.-R. Michel, "Tubular nephrotoxicity of water-soluble iodinated contrast media," Investigative Radiology, vol. 15, no. 6, supplement, pp. S54-S60, 1980.

[109] P. M. Treuting and J. Kowalewska, "Artefacts," in A Practical Guide to the Histology of the Mouse, C. L. C. Scudamore, Ed., pp. 77-79, John Wiley \& Sons, New York, NY, USA, 2014.

[110] P. Prentø and H. Lyon, "Commercial formalin substitutes for histopathology," Biotechnic and Histochemistry, vol. 72, no. 5, pp. 273-282, 1997.

[111] R. C. Johnson, B. J. Dovey-Hartman, J. Syed et al., "Vacuolation in renal tubular epithelium of Cd-1 mice: an incidental finding," Toxicologic Pathology, vol. 26, no. 6, pp. 789-792, 1998.

[112] Z. Ebcioglu, D. J. Cohen, R. J. Crew et al., "Osmotic nephrosis in a renal transplant recipient," Kidney International, vol. 70, no. 10, pp. 1873-1876, 2006.

[113] H. F. Helmholz, "Renal changes in the rabbit resulting from intravenous injection of hypertonic solution of sucrose," The Journal of Pediatrics, vol. 3, no. 1, pp. 144-157, 1933.

[114] M. Dickenmann, T. Oettl, and M. J. Mihatsch, "Osmotic nephrosis: acute kidney injury with accumulation of proximal tubular lysosomes due to administration of exogenous solutes," American Journal of Kidney Diseases, vol. 51, no. 3, pp. 491-503, 2008.

[115] W. A. D. Anderson and W. R. Bethea Jr., "Renal lesions following administration of hypertonic solutions of sucrose: report of six cases," The Journal of the American Medical Association, vol. 114, no. 20, pp. 1983-1987, 1940.

[116] A. C. Allen, "Diseases of the tubules," in The Kidney. Medical and Surgical Diseases, A. C. Allen, Ed., vol. diseases, pp. 207-298, Grune \& Stratton, New York, NY, USA, 1951.

[117] A. Bendele, J. Seely, C. Richey, G. Sennello, and G. Shopp, "Short communication: renal tubular vacuolation in animals treated with polyethylene-glycol-conjugated proteins," Toxicological Sciences, vol. 42, no. 2, pp. 152-157, 1998. 
[118] C. Legendre, E. Thervet, B. Page, A. Percheron, L. H. Noël, and H. Kreis, "Hydroxyethylstarch and osmotic-nephrosis- like lesions in kidney transplantation," The Lancet, vol. 342, no. 8865, pp. 248-249, 1993.

[119] C. Jungheinrich and T. A. Neff, "Pharmacokinetics of hydroxyethyl starch," Clinical Pharmacokinetics, vol. 44, no. 7, pp. 681699, 2005.

[120] E. A. J. Hoste and W. De Corte, "Implementing the Kidney Disease: improving global outcomes/acute kidney injury guidelines in ICU patients," Current Opinion in Critical Care, vol. 19, no. 6, pp. 544-553, 2013.

[121] E. I. Christensen and A. B. Maunsbach, "Dextran is resistant to lysosomal digestion in kidney tubules," Virchows Archiv B Cell Pathology Including Molecular Pathology, vol. 37, no. 1, pp. 4959, 1981.

[122] A. B. Maunsbach, S. C. Madden, and H. Latta, "Light and electron microscopic changes in proximal tubules of rats after administration of glucose, mannitol, sucrose, or dextran," Laboratory Investigation, vol. 11, pp. 421-432, 1962.

[123] A. Z. Nomani, Z. Nabi, H. Rashid et al., "Osmotic nephrosis with mannitol: review article," Renal Failure, vol. 36, no. 7, pp. 11691176, 2014.

[124] P. Liss, P. Hansell, P.-O. Carlsson, A. Fasching, and F. Palm, "Iodinated contrast media decrease renomedullary blood flow. A possible cause of contrast media-induced nephropathy," Advances in Experimental Medicine and Biology, vol. 645, pp. 213-218, 2009.

[125] T. Nonoyama and R. Fukuda, "Drug-induced phospholipidosis-pathological aspects and its prediction," Journal of Toxicologic Pathology, vol. 21, no. 1, pp. 9-24, 2008.

[126] H. A. Lindberg, M. H. Wald, and M. Barker, "Renal changes following administration of hypertonic solutions (50 per cent sucrose, 50 per cent d-sorbitol, ${ }^{\star} 50$ per cent dextrose and 10 per cent sodium chloride)," Archives of Internal Medicine, vol. 63, no. 5, pp. 907-918, 1939.

[127] G. Simon, F. Chatelanat, and A. Falbriard, "Experimental nephrosis due to inulin: light and electron microscopic studies," Laboratory Investigation, vol. 13, pp. 1381-1393, 1964.

[128] S. Hansen-Schmidt, J. Silomon, and F. Keller, "Osmotic nephrosis due to high-dose immunoglobulin therapy containing sucrose (but not with glycine) in a patient with immunoglobulin A nephritis," American Journal of Kidney Diseases, vol. 28, no. 3, pp. 451-453, 1996.

[129] D. B. Winward and M. T. Brophy, "Acute renal failure after administration of intravenous immunoglobulin: review of the literature and case report," Pharmacotherapy, vol. 15, no. 6, pp. 765-772, 1995.

[130] Centers for Disease Control and Prevention, "Renal insufficiency and failure associated with immune globulin intravenous therapy-United States, 1985-1998," Morbidity and Mortality Weekly Report, vol. 48, no. 24, pp. 518-521, 1999.

[131] B. Chacko, G. T. John, N. Balakrishnan, M. G. Kirubakaran, and C. K. Jacob, "Osmotic nephropathy resulting from maltosebased intravenous immunoglobulin therapy," Renal Failure, vol. 28, no. 2, pp. 193-195, 2006.

[132] S. L. Schwartz and C. B. Johnson, "Pinocytosis as the cause of sucrose nephrosis," Nephron, vol. 8, no. 3, pp. 246-254, 1971.

[133] G. Gluhovschi, F. Gadalean, C. Gluhovschi et al., "Urinary biomarkers in assessing the nephrotoxic potential of gentamicin in solitary kidney patients after 7 days of therapy," Renal Failure, vol. 36, no. 4, pp. 534-540, 2014.
[134] W. G. Guder and B. D. Ross, "Enzyme distribution along the nephron," Kidney International, vol. 26, no. 2, pp. 101-111, 1984.

[135] R. Hofmeister, A. S. Bhargava, and P. Günzel, "The use of urinary $\mathrm{N}$-acetyl- $\beta$-D-glucosaminidase (NAG) for the detection of contrast-media-induced 'osmotic nephrosis' in rats," Toxicology Letters, vol. 50, no. 1, pp. 9-15, 1990.

[136] E. Seeliger, M. Ladwig, L. Sargsyan, K. Cantow, P. B. Persson, and B. Flemming, "Proof of principle: hydration by lowosmolar mannitol-glucose solution alleviates undesirable renal effects of an iso-osmolar contrast medium in rats," Investigative Radiology, vol. 47, no. 4, pp. 240-246, 2012.

[137] B. Yang, J. Xu, F. Xu et al., "Intravascular administration of mannitol for acute kidney injury prevention: a systematic review and meta-analysis," PLoS ONE, vol. 9, no. 1, Article ID e85029, 2014.

[138] G. Laurent, B. K. Kishore, and P. M. Tulkens, "Aminoglycosideinduced renal phospholipidosis and nephrotoxicity," Biochemical Pharmacology, vol. 40, no. 11, pp. 2383-2392, 1990.

[139] M. R. Rudnick, J. S. Berns, R. M. Cohen, and S. Goldfarb, "Contrast media-associated nephrotoxicity," Seminars in Nephrology, vol. 17, no. 1, pp. 15-26, 1997.

[140] B. Ryffel, B. M. Foxwell, A. Gee, B. Greiner, G. Woerly, and M. J. Mihatsch, "Cyclosporine-relationship of side effects to mode of action," Transplantation, vol. 46, no. 2, supplement, pp. 90S96S, 1988.

[141] M. Naesens, D. R. J. Kuypers, and M. Sarwal, "Calcineurin inhibitor nephrotoxicity," Clinical Journal of the American Society of Nephrology, vol. 4, no. 2, pp. 481-508, 2009.

[142] P. Walday, I. F. Heglund, K. Golman, J. Cornacoff, and E. Holtz, "Renal effects of iodixanol in experimental animals," Acta Radiologica. Supplementum, vol. 399, pp. 204-212, 1995.

[143] M. Dobrota, C. J. Powell, E. Holtz, A. Wallin, and H. Vik, "Biochemical and morphological effects of contrast media on the kidney," Acta Radiologica. Supplementum, vol. 399, pp. 196-203, 1995.

[144] C. J. Powell, M. Dobrota, E. Holtz, and H. Vik, "The histopathology of X-ray contrast medium induced renal droplets (vacuoles)," European Radiology, vol. 5, no. 2, pp. 176-180, 1995.

[145] J. Wang, Y. Zhang, X. Yang et al., "Time course study on the effects of iodinated contrast medium on intrarenal water transport function using diffusion-weighted MRI," Journal of Magnetic Resonance Imaging, vol. 35, no. 5, pp. 1139-1144, 2012.

[146] Y.-D. Zhang, J. Wang, J. Zhang, X. Wang, and X. Jiang, "Effect of iodinated contrast media on renal function evaluated with dynamic three-dimensional MR renography," Radiology, vol. 270, no. 2, pp. 409-415, 2014.

[147] Y. Zhang, J. Wang, X. Yang et al., “The serial effect of iodinated contrast media on renal hemodynamics and oxygenation as evaluated by ASL and BOLD MRI," Contrast Media and Molecular Imaging, vol. 7, no. 4, pp. 418-425, 2012.

[148] J.-H. Wang, K. Ren, W.-G. Sun, L. Zhao, H.-S. Zhong, and K. Xu, "Effects of iodinated contrast agents on renal oxygenation level determined by blood oxygenation level dependent magnetic resonance imaging in rabbit models of type 1 and type 2 diabetic nephropathy," BMC Nephrology, vol. 15, no. 1, article 140, 2014.

[149] T. S. Larson, K. Hudson, J. I. Mertz, J. C. Romero, and F. G. Knox, "Renal vasoconstrictive response to contrast medium. The role of sodium balance and the renin-angiotensin system," The Journal of Laboratory and Clinical Medicine, vol. 101, no. 3, pp. 385-391, 1983.

[150] R. O. Danford, L. B. Talner, and A. J. Davidson, "Effect of graded osmolaltities of saline solution and contrast media on renal 
extraction of pah in the dog," Investigative Radiology, vol. 4, no. 5, pp. 301-305, 1969.

[151] W. A. Sorby and R. J. Hoy, "Renal arteriography and renal function. The short-term effect of aortography, selective renal arteriography, adrenalin suppression and renal venography on PAH extraction ratio," Australasian Radiology, vol. 12, no. 3, pp. 252-255, 1968.

[152] C. B. Higgins, "Renal circulation," in Radiocontrast Agents, M. Solioz, Ed., Springer, Berlin, Germany, 1984.

[153] C. Gospos, N. Freudenberg, J. Staubesand, K. Mathias, and X. Papacharlampos, "The effect of contrast media on the aortic endothelium of rats," Radiology, vol. 147, no. 3, pp. 685-688, 1983.

[154] R. Battenfeld, A. E. R. Khater, W. Drommer, P. Guenzel, and F.-J. Kaup, "Ioxaglate-induced light and electron microscopic alterations in the renal proximal tubular epithelium of rats," Investigative Radiology, vol. 26, no. 1, pp. 35-39, 1991.

[155] C. J. Powell, M. Dobrota, and E. Holtz, "Studies on the mechanism of radiological contrast media induced renal failure," in Nephrotoxicity, P. H. Bach and E. A. Lock, Eds., pp. 463-468, Springer US, 1989.

[156] S. W. Murphy, B. J. Barrett, and P. S. Parfrey, "Contrast nephropathy," Journal of the American Society of Nephrology, vol. 11, no. 1, pp. 177-182, 2000.

[157] K. Hardiek, R. E. Katholi, V. Ramkumar, and C. Deitrick, "Proximal tubule cell response to radiographic contrast media," American Journal of Physiology-Renal Physiology, vol. 280, no. 1, pp. F61-F70, 2001.

[158] M. C. Heinrich, M. K. Kuhlmann, A. Grgic, M. Heckmann, B. Kramann, and M. Uder, "Cytotoxic effects of ionic highosmolar, nonionic monomeric, and nonionic iso-osmolar dimeric iodinated contrast media on renal tubular cells in vitro," Radiology, vol. 235, no. 3, pp. 843-849, 2005.

[159] C. Haller, C. S. Schick, M. Zorn, and W. Kübier, "Cytotoxicity of radiocontrast agents on polarized renal epithelial cell monolayers," Cardiovascular Research, vol. 33, no. 3, pp. 655-665, 1997.

[160] M. Heinrich, M. Scheer, M. Heckmann, W. Bautz, and M. Uder, "Reversibility and time-dependency of contrast medium induced inhibition of 3-(4,5-dimethylthiazol-2-yl)-2,5-diphenyl-tetrazolium bromide (MTT) conversion in renal proximal tubular cells in vitro: comparison of a monomeric and a dimeric nonionic iodinated contrast medium," Investigative Radiology, vol. 42, no. 11, pp. 732-738, 2007.

[161] C. S. Schick and C. Haller, "Comparative cyotoxicity of ionic and non-ionic radiocontrast agents on MDCK cell monolayers in vitro," Nephrology Dialysis Transplantation, vol. 14, no. 2, pp. 342-347, 1999.

[162] R. A. Zager, A. C. M. Johnson, and S. Y. Hanson, "Radiographic contrast media-induced tubular injury: evaluation of oxidant stress and plasma membrane integrity," Kidney International, vol. 64, no. 1, pp. 128-139, 2003.

[163] G. Romano, C. Briguori, C. Quintavalle et al., "Contrast agents and renal cell apoptosis," European Heart Journal, vol. 29, no. 20, pp. 2569-2576, 2008.

[164] H. D. Humes, D. A. Hunt, and M. D. White, "Direct toxic effect of the radiocontrast agent diatrizoate on renal proximal tubule cells," American Journal of Physiology-Renal Fluid and Electrolyte Physiology, vol. 252, no. 2, pp. F246-F255, 1987.

[165] D. S. Humes, D. A. Cieslinski, and J. M. Messana, "Pathogenesis of radiocontrast-induced acute renal failure: comparative nephrotoxicity of diatrizoate and iopamidol," Diagnostic Imaging, vol. 9, 1987.
[166] A. Aurelio and A. Durante, "Contrast-induced nephropathy in percutaneous coronary interventions: pathogenesis, risk factors, outcome, prevention and treatment," Cardiology, vol. 128, no. 1, pp. 62-72, 2014.

[167] I. Hizóh, J. Sträter, C. S. Schick, W. Kübier, and C. Haller, "Radiocontrast-induced DNA fragmentation of renal tubular cells in vitro: role of hypertonicity," Nephrology Dialysis Transplantation, vol. 13, no. 4, pp. 911-918, 1998.

[168] I. Hizoh and C. Haller, "Radiocontrast-induced renal tubular cell apoptosis: hypertonic versus oxidative stress," Investigative Radiology, vol. 37, no. 8, pp. 428-434, 2002.

[169] A. Peer, Z. Averbukh, S. Berman, D. Modai, M. Averbukh, and J. Weissgarten, "Contrast media augmented apoptosis of cultured renal mesangial, tubular, epithelial, endothelial, and hepatic cells," Investigative Radiology, vol. 38, no. 3, pp. 177-182, 2003.

[170] C. Quintavalle, M. Brenca, F. De Micco et al., "In vivo and in vitro assessment of pathways involved in contrast mediainduced renal cells apoptosis," Cell Death \& Disease, vol. 2, no. 5, article e155, 2011.

[171] S. N. Heyman, C. Rosenberger, and S. Rosen, "Experimental ischemia-reperfusion: biases and mythsthe proximal vs. distal hypoxic tubular injury debate revisited," Kidney International, vol. 77, no. 1, pp. 9-16, 2010.

[172] T. Kaucsár, M. Godó, C. Révész et al., "Urine/plasma neutrophil gelatinase associated lipocalin ratio is a sensitive and specific marker of subclinical acute kidney injury in mice," PLoS ONE, vol. 11, no. 1, article 0148043, 2016.

[173] L. Hofmann, S. Simon-Zoula, A. Nowak et al., "BOLD-MRI for the assessment of renal oxygenation in humans: acute effect of nephrotoxic xenobiotics," Kidney International, vol. 70, no. 1, pp. 144-150, 2006.

[174] A. O. Oyekan, "Contributions of nitric oxide and prostanoids and their signaling pathways to the renal medullary vasodilator effect of U46619 (9-11-dideoxy-11 alpha,9a-epoxymethanoprostaglandin $\mathrm{F}(2 \mathrm{a})$ ) in the rat," Journal of Pharmacology and Experimental Therapeutics, vol. 304, no. 2, pp. 507-512, 2003.

[175] L. S. Chawla and P. L. Kimmel, "Acute kidney injury and chronic kidney disease: an integrated clinical syndrome," Kidney International, vol. 82, no. 5, pp. 516-524, 2012. 


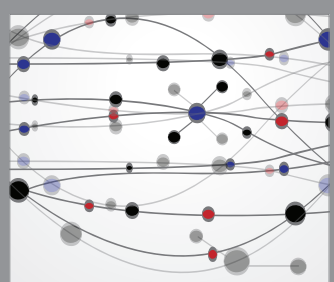

The Scientific World Journal
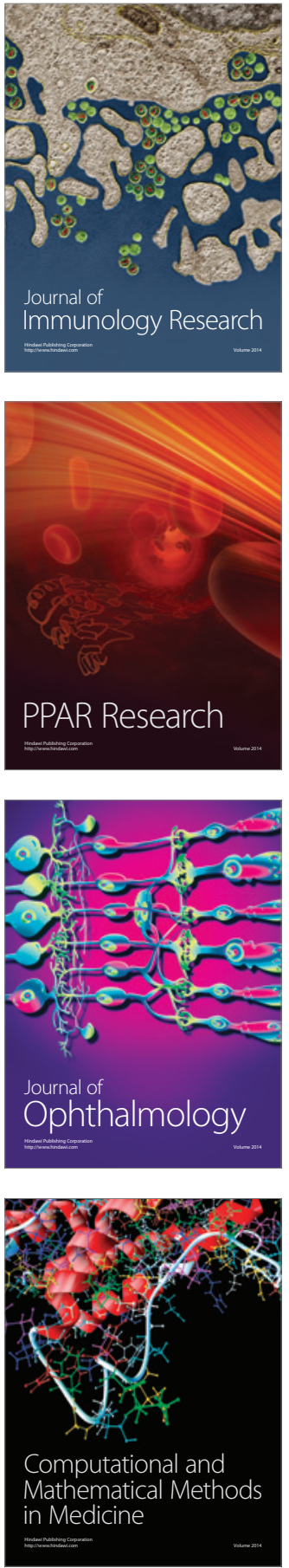

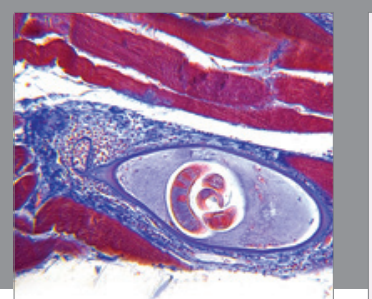

Gastroenterology Research and Practice

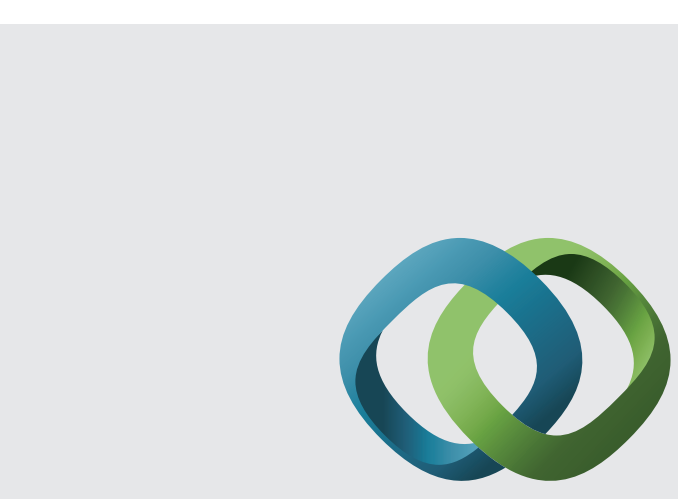

\section{Hindawi}

Submit your manuscripts at

http://www.hindawi.com
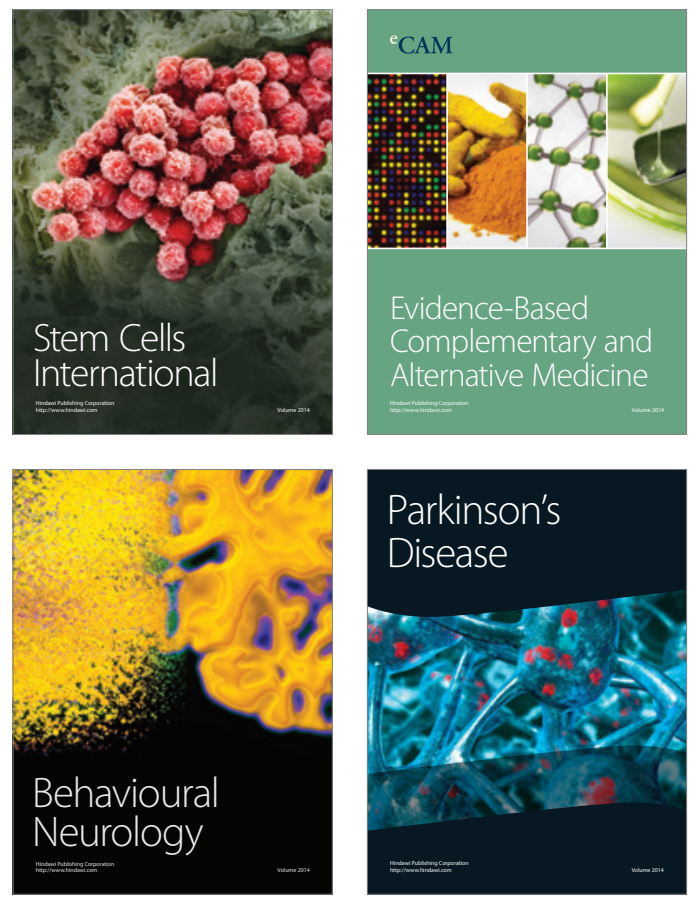
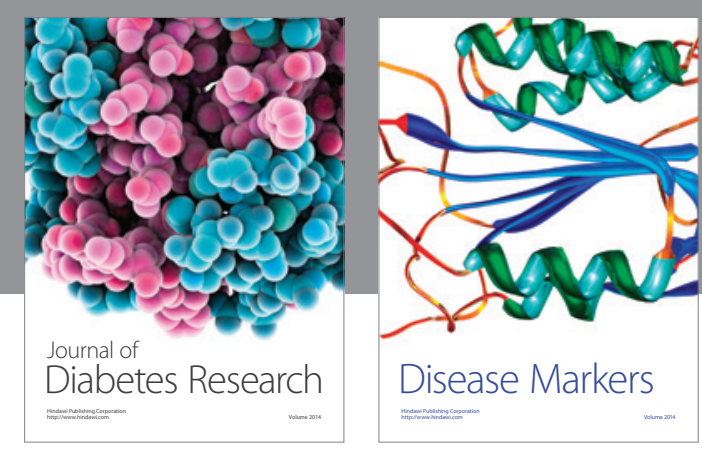

Disease Markers
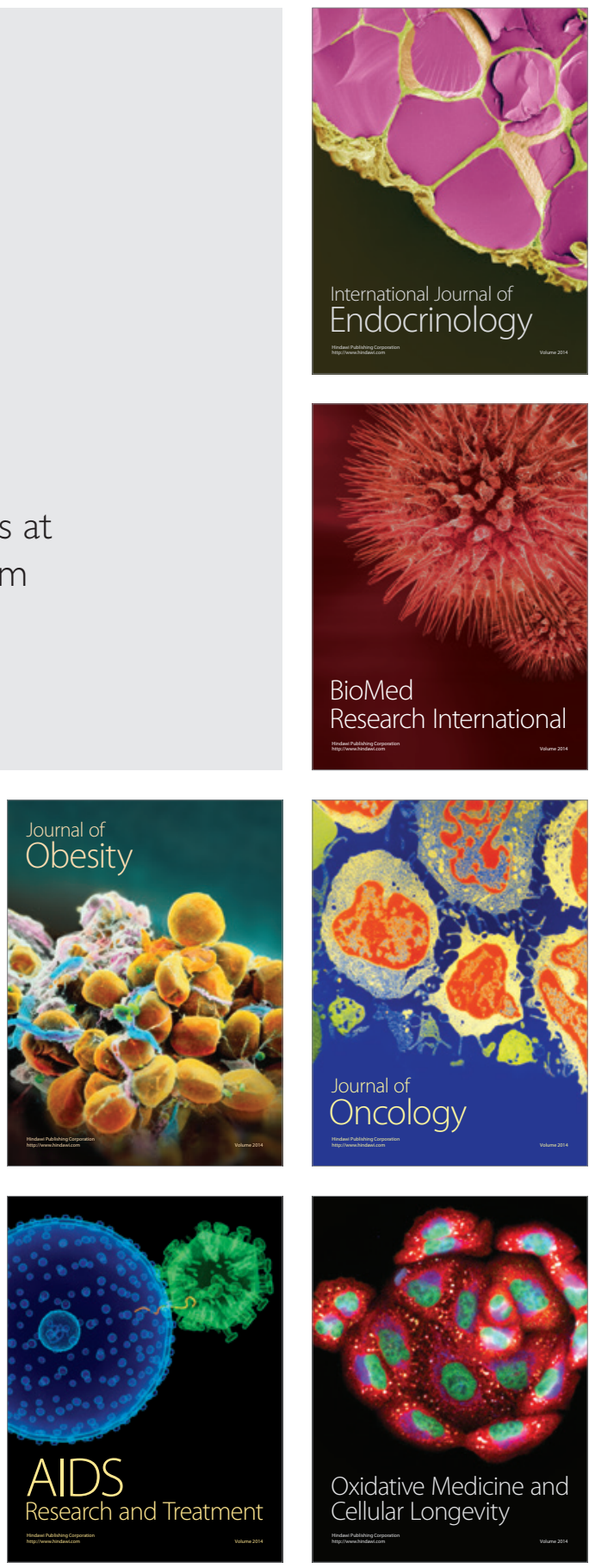